\title{
A multicriteria facility location model for municipal solid waste management in North Greece
}

\author{
Erhan Erkut ${ }^{\mathrm{a}, *}$, Avraam Karagiannidis ${ }^{\mathrm{b}}$, George Perkoulidis ${ }^{\mathrm{b}}$, \\ Stevanus A. Tjandra ${ }^{\mathrm{c}}$ \\ ${ }^{a}$ Faculty of Business Administration, Bilkent University, Ankara, Turkey \\ ${ }^{\mathrm{b}}$ Laboratory of Heat Transfer and Environmental Engineering, Department of Mechanical Engineering, \\ Box 483, Aristotle University, GR-54124 Thessaloniki, Greece \\ ${ }^{\mathrm{c}}$ School of Business, University of Alberta, Edmonton, Alberta, Canada T6G 2R6
}

Available online 17 November 2006

\begin{abstract}
Up to 2002, Hellenic Solid Waste Management (SWM) policy specified that each of the country's 54 prefectural governments plan its own SWM system. After 2002, this authority was shifted to the country's 13 regions entirely. In this paper, we compare and contrast regional and prefectural SWM planning in Central Macedonia. To design the prefectural plan, we assume that each prefecture must be self-sufficient, and we locate waste facilities in each prefecture. In contrast, in the regional plan, we assume cooperation between prefectures and locate waste facilities to serve the entire region. We present a new multicriteria mixed-integer linear programming model to solve the location-allocation problem for municipal SWM at the regional level. We apply the lexicographic minimax approach to obtain a "fair" nondominated solution, a solution with all normalized objectives as equal to one another as possible. A solution to the model consists of locations and technologies for transfer stations, material recovery facilities, incinerators and sanitary landfills, as well as the waste flow between these locations.
\end{abstract}

(C) 2006 Elsevier B.V. All rights reserved.

Keywords: Environment; Location; Municipal solid waste; Multiple criteria analysis

\section{Introduction}

Municipal solid waste (MSW), commonly known as trash or garbage, consists of everyday items such

\footnotetext{
* Corresponding author. Tel.: +1 780492 3068; fax: +1 780492 3325 .

E-mail addresses: erkut@bilkent.edu.tr (E. Erkut),makis@ aix.meng.auth.gr (A. Karagiannidis), gperk@aix.meng.auth.gr (G. Perkoulidis), Stevanus.Tjandra@ualberta.ca (S.A. Tjandra).
}

as product packaging, grass clippings, furniture, clothing, bottles, food scraps, newspapers, appliances, paint and batteries. If not dealt with properly, waste can create serious environmental and health problems. In this paper, we focus on MSW management in the region of Central Macedonia in Greece. We develop a mixed-integer linear programming model with multiple objectives to solve the location-allocation problem, including the technology selection of transfer stations, material recovery facilities (MRFs), incinerators, and sanitary 
landfills. Our model is more comprehensive and complex than the models in the literature, as we consider different waste processing technologies in MRFs and incinerators. We take economic and environmental criteria into account.

Our research does not involve real decision makers (DMs) from prefectures of the region. We assume that all objectives are equally important, and we aim for a "fair" solution, i.e., a solution with all normalized objective function values as close to one another as possible. A popular fairness-oriented approach in the literature is the lexicographic mini$\max$ (see e.g. [17,19]). Lexicographic minimax solutions are also called lexicographic max-ordering [9], lexicographic centers in location problems [20], and nucleolar solutions in game theory [18]. A variant of this approach, lexicographic maximin, is used for telecommunication network design (see e.g. $[21,23]$ ). Following Ogryczak et al. [21], we discuss the conversion of the original lexicographic minimax problem to a lexicographic minimization problem. This enables us to use the standard sequential algorithm for lexicographic minimization. To the best of our knowledge, this paper presents the first attempt to apply the fairness concept of multiobjective optimization to solid waste management.

In Greece each region consists of a number of prefectures. Legislation in Greece specified that each prefecture of a region should plan its own solid waste management system. These plans were financially supported by the region. Recently the planning authority shifted to the regions. We apply our model to compare and contrast regional and prefectural solid waste management planning. In the prefectural planning, we look for the optimal location and allocation decision of waste facilities per prefecture taking into account multiple criteria. In the regional planning, we unite all prefectures in the Central Macedonia region and look for the optimal location and allocation decision of waste facilities that cover the needs of all seven prefectures in this region.

The paper is organized as follows. Section 2 contains an introduction to the municipal solid waste problem in Greece. Section 3 discusses the relevant literature. In Section 4, we provide the formulation of the model (the notation is in the Appendix). In Section 5, we provide a short review of multiobjective mathematical programming and lexicographic minimax approach. We also discuss the fair solution in this section. Section 6 contains our empirical results; namely an analysis of prefectural versus regional MSW management planning in Central Macedonia. Finally, we conclude the paper with a discussion of possible further research in Section 7.

\section{Municipal solid waste management in Greece}

As a country's population increases and its standard of living improves, its amount of waste production increases and its landfill space becomes scarce. The MSW production in Greece increased from 3900 thousand tons (kt) in 1997 to $4559 \mathrm{kt}$ in 2001 (see Fig. 1). The Hellenic MSW consists mainly of organics $(47 \%)$ and paper $(20 \%)$, as illustrated in Fig. 2.

MSW management in Greece is different than that of most European Union (EU) countries. The quantity of waste in Greece continues to be somewhat lower than in other European countries, reflecting a less intense consumption pattern. The composition of waste in Greece is also different, being high in biodegradable materials and low in packaging materials. These positive characteristics are balanced by certain negative features in the waste management sector. The high number of open dump sites (reduced from over 5500 in 1990 to 1260 in 2004) constitutes the most negative element, and the percentage of useful material recovered is low.

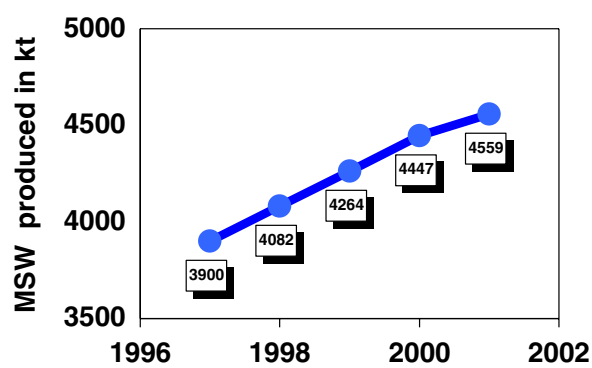

Fig. 1. Trends in MSW generation in Greece 1997-2001 [6].

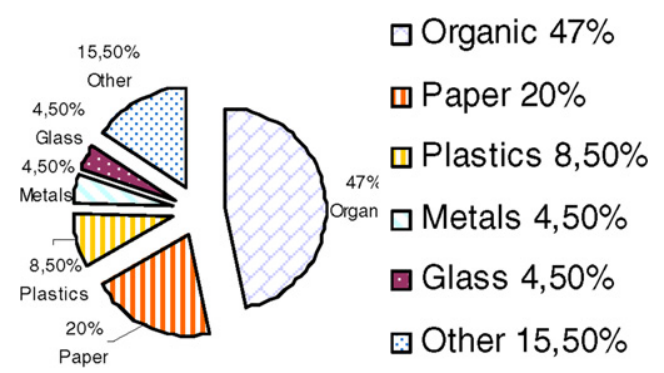

Fig. 2. Waste fractions of MSW in 2001 in Greece [6]. 
Greece, within the framework of the EU, is planning its solid waste policy with the goals of protecting human health and preserving the natural environment. Greece has developed a comprehensive legislative system that harmonizes with the European legal framework. Various measures have been put in place for the integrated solid waste management (ISWM) policy. This policy promotes waste reduction programs, recycling, and energy recovery rather than landfills for waste disposal. The recycle-at-the-source programme, as part of the ISWM policy, has the following quantitative goals by the end of 2005: utilising $50-65 \%$ of the weight of packaging waste; recycling $25-45 \%$ of the weight of packaging waste; and recycling $15 \%$ of the packaging material [25]. In order to reach these goals, facilities for material recovery are constructed in various municipalities. In the future, Hellenic national legislation will continue to comply with EU regulations and directives on waste management. Greece and the EU aim for a significant decrease in the amount of waste generated, through new waste prevention initiatives, better use of resources, and a shift to more sustainable consumption patterns. Specific EU targets include reducing the quantity of waste disposed by $20 \%$ by 2010 and by $50 \%$ by 2050 , with special emphasis on hazardous waste.

Greece consists of 13 administrative regions, which are further subdivided into 54 prefectures. We focus our discussion on the MSW management

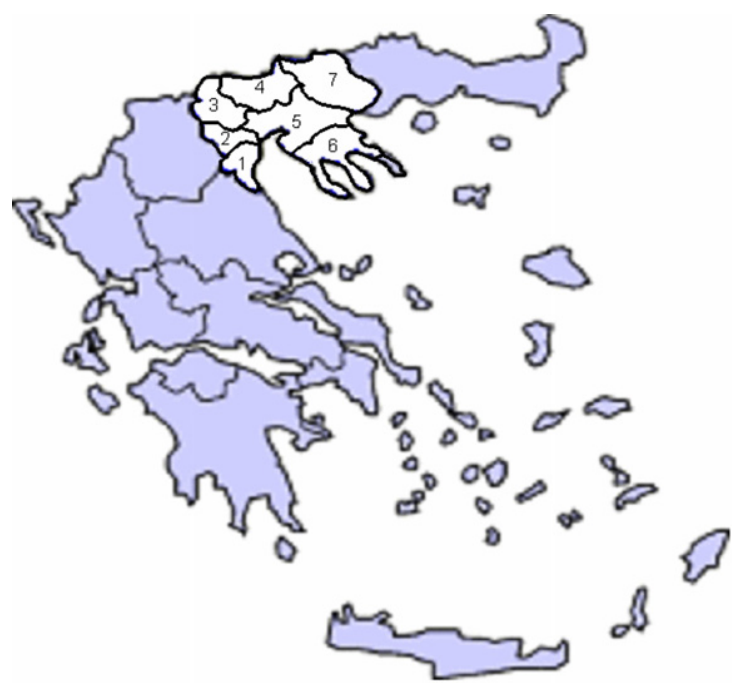

Fig. 3. Administrative region of Central Macedonia in North Greece and its seven prefectures: (1) Pieria, (2) Imathia, (3) Pella, (4) Kilkis, (5) Thessaloniki, (6) Chalkidiki, and (7) Serres. system of the Central Macedonia region situated in North Greece (Fig. 3). This region has the largest area and the second largest population among all regions. It comprises $14.2 \%$ of the country's total area $\left(18,779 \mathrm{~km}^{2}\right)$ and consists of seven prefectures: Pieria, Imathia, Pella, Kilkis, Thessaloniki, Chalkidiki, and Serres, as shown in Fig. 3. The areas and populations of these prefectures are shown in Table 1.

In the region of Central Macedonia, $713 \mathrm{kt}$ of waste was generated in 2001, from which only $10.5 \%$ ended up in sanitary landfills, whereas $39.6 \%$ and $49.9 \%$ ended up in uncontrolled and semi-controlled landfills, respectively.

The trend in total waste generation is shown in Fig. 4. According to Greek legislation, until 2020, $50 \%$ (107 kt) of the estimated $214.5 \mathrm{kt}$ of packaging material and $78.9 \%(450 \mathrm{kt})$ of the $570 \mathrm{kt}$ of organics should be diverted from landfills to material recovery facilities.

The ISWM system is structured into four phases of collection, transportation, processing, and disposal $[3,13]$. MSW collection initially involves picking up refuse at the sources via collection vehicles. Between the waste collection and the waste disposal stages, some processing operations such as separation,

\section{Table 1}

The distribution of population and size of seven prefectures in the region of Central Macedonia

\begin{tabular}{llc}
\hline Prefecture & $\begin{array}{l}\text { Area }\left(\mathrm{km}^{2}\right)(\% \text { of the } \\
\text { area of Greece) }\end{array}$ & $\begin{array}{l}\text { Population }(\% \text { of the } \\
\text { population of Greece) }\end{array}$ \\
\hline Pieria & $1516(1.1 \%)$ & $129,846(1.2 \%)$ \\
Imathia & $1701(1.3 \%)$ & $144,172(1.3 \%)$ \\
Pella & $2506(1.9 \%)$ & $144,340(1.3 \%)$ \\
Kilkis & $2519(1.9 \%)$ & $89,611(0.8 \%)$ \\
Thessaloniki & $3683(2.8 \%)$ & $1,046,851(9.5 \%)$ \\
Chalkidiki & $2886(2.2 \%)$ & $92,117(0.8 \%)$ \\
Serres & $3968(3.0 \%)$ & $200,916(1.8 \%)$ \\
\hline
\end{tabular}

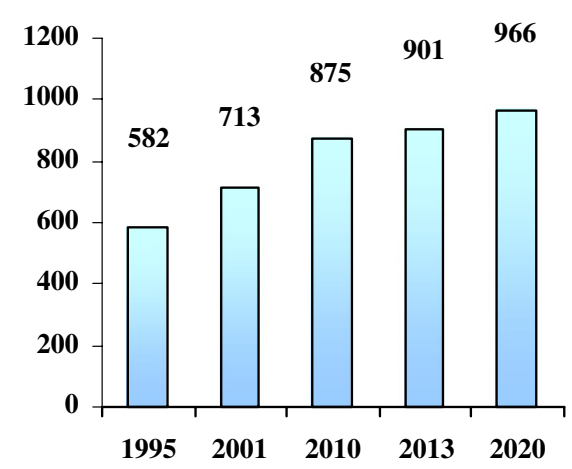

Fig. 4. Trend in total waste generation in Central Macedonia (kt). 


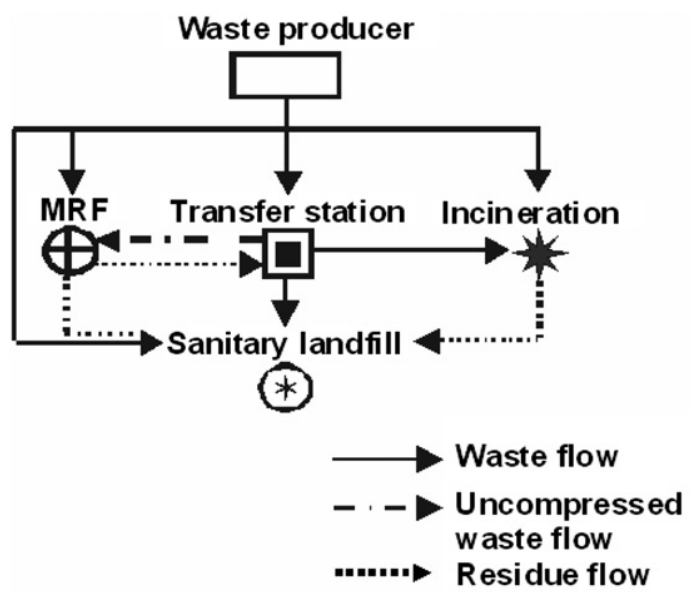

Fig. 5. The flow of MSW.

compaction, composting, and incineration, might be employed either to reduce the space needed to store the waste, recycle material, or recover energy. The conceptual framework of the waste flow system is presented in Fig. 5. The waste flow starts from the waste producers and continues either to the transfer station, material recovery facility (MRF), incinerator (i.e., waste-to-energy facility), or sanitary landfill. At a transfer station, the MSW is unloaded from collection vehicles, held briefly, and reloaded onto long-distance transport vehicles for shipment to landfills or to other treatment or disposal facilities.

An MRF processes recyclables in order to recover commodity-grade materials for sale, or a mixed-material fraction for processing or conversion, for example, into refuse-derived fuel (RDF) or compost. Composting is a biological process that converts organic material into a stable humus-like product called compost. Three MRF types are considered in this work: composting (aerobic digestion with material recovery), RDF-producing (aerobic digestion with material and energy recovery), and anaerobic digestion (material and energy recovery). Anaerobic digestion is a biological process that decomposes organic waste in order to produce biogas $\left(\mathrm{CH}_{4}\right.$ and $\left.\mathrm{CO}_{2}\right)$ and fertilizer. It produces material and renewable energy, while reducing greenhouse gas emissions and the volume of waste going to sanitary landfills.

Incineration involves the destruction of organic and combustible waste at high temperatures (650$\left.1100{ }^{\circ} \mathrm{C}\right)$. Three incinerator types are considered, mass-burn, rotary kiln, and combined pyrolysis and gasification. The most common technology is mass-burn. It involves the combustion of unpro- cessed or minimally processed refuse. Mass-burn facilities process raw waste, which is not shredded, sized, or separated before combustion. Large items such as refrigerators and stoves, batteries, and hazardous waste materials are removed before combustion. A rotary kiln incinerator is beneficial when the municipal waste has high moisture content. It moves the trash through the combustion process and finally into the ash quenching pit. Pyrolysis and gasification are thermal processes that use high temperatures to break down waste containing carbon. Three phases are obtained after pyrolysis: solid (char), liquid (water and oils) and gas (light hydrocarbons, $\mathrm{H}_{2}, \mathrm{CO}$ and $\mathrm{CO}_{2}$ ). The gasification process then breaks down the remaining hydrocarbons into low calorific fuel gas, which can be used as fuel for power and heat generation.

According to the waste flow shown in Fig. 5, MSW management involves a number of issues, such as the selection of solid waste treatment technologies, the location of solid waste treatment facilities and landfills, the capacity-expansion strategies of the sites, waste flow allocation to processing facilities and landfills, partitioning the service territory into districts, selecting collection days for each district and waste type, determining fleet composition, routing, scheduling and monitoring collection vehicles, benchmarking waste collection services, etc.

\section{Operational research and solid waste management}

Computerised systems based on OR techniques can help decision makers achieve remarkable cost savings. As the waste problem gets more acute, site selection for waste facilities becomes conflict-ridden, and the decision is usually met with considerable local opposition, e.g., with BANANA (Built Absolutely Nothing Anywhere Near Anyone), LULU (Locally Unwanted Land Use), NIMBY (Not in My Back Yard), NOPE (Not On Planet Earth), or NOTE (Not Over There Either) arguments. Therefore, the solution should not be only cost effective but also environmentally and socially acceptable. Hence, the waste management facility location-allocation problem is characterised by multiple, often conflicting objectives. This condition has led several authors to propose multicriteria decision approaches to the problem. Multiobjective waste facility location-allocation models take environmental and economic criteria into account $[4,5,12-$ 14], whereas single objective models consider only economic criteria $[1,2,10,11,15]$. 
Kirca and Erkip [15] proposed a location model of transfer stations to minimize the total transportation cost. This model accounted for the technology selection of loading-unloading facilities and for the type and number of transfer vehicles. Although the model is static, by experimenting with data from different prospected years, one can determine the timing of investment for transfer stations.

Caruso et al. [4] developed a location-allocation model for planning process plants and sanitary landfills for urban solid waste. They considered technologies of incineration, composting, and recycling for a process plant. Their model minimized the total cost (i.e., opening and transportation costs), amount of final disposal to the sanitary landfill, and environmental impact. They proposed an iterative heuristic method consisting of six (also iterative) heuristic procedures and run hierarchically to produce a subset of approximate efficient solutions using the weighted sum technique. Initially, the heuristic method considers the transport from waste producers to process plants. Once the plants for this first phase are located, transport to sanitary landfills is considered. The main cycle of the heuristic method is due to weight recomputation. The reference point method is then used to help the decision maker identify the final solution.

Karagiannidis et al. [14] proposed a set of multiple criteria, which cover social, environmental, financial, and technical aspects, for dealing with optimization of regional solid waste management. Karagiannidis and Moussiopoulos [13] proposed a modeling framework for regional solid waste management that accounted for the four level waste facility hierarchy: transfer station, material recovery facility, thermal treatment plant (i.e., incinerator), and sanitary landfill.

Hokkanen and Salminen [12] used the decisionaid method ELECTRE III to select a solid waste management system in the Oulu district in Northern Finland, with the following eight criteria: cost per ton, technical reliability, global effects, local and regional health effects, acidic releases, surface water dispersed releases, number of employees, and amount of recovered waste. Twenty-two alternatives under either decentralized or centralized management systems were examined, with various treatment methods such as composting, RDF-combustion, and landfill.

Antunes [2] developed a mixed-integer optimization model to determine the location and size of transfer stations and sanitary landfills. The model has as a single objective to minimize total transportation and opening costs, and was applied to central Portugal.

Chambal et al. [5] developed a multiple-objective decision analysis model to select the best MSW management strategy. This model is based upon the hierarchy of waste management objectives expressed by the decision maker. The value-focused thinking method helped to create the decision maker's fundamental objectives hierarchy. This hierarchy consists of a single overall (top-tier) objective, which is separated into an appropriate number of bottom-tier objectives. Each bottom-tier objective is then quantified into an evaluation measure score. The preferences of the decision maker, represented by weights associated with each objective, determine the conversion from evaluation measure scores to value units.

\section{Model formulation}

The proposed model is a mixed-integer linear programming model with multiple objectives with respect to economic and environmental criteria. The notations used for the formulation of the model are given in the Appendix. There are two kinds of variables used in the mathematical formulation of this model:

- 0-1 facility location variables $\varphi, \chi, \psi, \omega$, where the variable has value one if the corresponding new facility is opened and zero otherwise,

- continuous waste flow variables $\alpha, \varepsilon, \varsigma, \zeta, \theta, \eta, \imath$, $\kappa, \delta$ representing the quantity of flow between facilities.

We denote $x$ as the vector of variables used in the model, i.e.,

$x:=(\varphi, \alpha, \chi, \varepsilon, \varsigma, \psi, \zeta, \theta, \omega, \eta, \imath, \kappa, \delta)$.

The proposed mathematical model can be stated as follows: Given a set of waste producers and the set of potential locations for transfer stations, MRFs, incinerators, and sanitary landfills, find the location and typology of those waste facilities so as to satisfy the following five objectives, which are usually in conflict.

1. Minimize the greenhouse effect (GHE). The greenhouse effect describes how greenhouse gases, including carbon dioxide $\left(\mathrm{CO}_{2}\right)$, methane $\left(\mathrm{CH}_{4}\right)$, nitrous oxide $\left(\mathrm{N}_{2} \mathrm{O}\right)$ and chlorofluorocarbons 
(CFCs) in the earth's atmosphere absorb the amount of heat escaping from the earth into the atmosphere, making the earth's surface warmer. Waste processing in MRF (anaerobic digestion), incinerators and landfills is considered to be the source of greenhouse gases. We define the greenhouse effect as a product of the amount of waste in the facility, and the greenhouse emission coefficient associated with the facility or its typology. It is represented in ton of $\mathrm{CO}_{2}$-equivalent and $\mathrm{CH}_{4}$ per year. The GHE objective function is formulated as

$$
\begin{aligned}
\min \operatorname{GHE}(x):= & \sum_{v \in V} \sum_{\rho \in P} A_{v}^{\mathrm{GHE}} c_{\rho}^{v}+\sum_{\xi \in E} \sum_{\sigma \in D} \Gamma_{\xi}^{\mathrm{GHE}} d_{\sigma}^{\xi} \\
& +\sum_{o \in O} \sum_{\tau \in T} E_{o}^{\mathrm{GHE}} e_{\tau}^{o} .
\end{aligned}
$$

2. Minimize the final disposal to the landfill (FIDI), i.e., the total amount (in tons/year) of waste and/ or residue brought to all landfills from all waste producers and other facilities

$$
\begin{aligned}
\min \operatorname{FIDI}(x):= & \sum_{i \in I} \sum_{o \in O} \sum_{\tau \in T} \eta_{i \tau}^{o} w_{\tau}^{o} \\
& +\sum_{\mu \in M} \sum_{\pi \in \Pi} \sum_{o \in O} \sum_{\tau \in T} \imath_{\pi \tau}^{\mu o} w_{\tau}^{o} \\
+ & \sum_{\rho \in P} \sum_{o \in O} \sum_{\tau \in T} \kappa_{\rho \tau}^{v o} w_{\tau}^{o} \\
& +\sum_{\xi \in E} \sum_{\sigma \in D} \sum_{o \in O} \sum_{\tau \in T} \delta_{\sigma \tau}^{\xi o} w_{\tau}^{o}
\end{aligned}
$$

or for short

$\min \operatorname{FIDI}(x):=\sum_{o \in O} \sum_{\tau \in T} e_{\tau}^{o} w_{\tau}^{o}$.

Thus, we wish to minimize the amount of waste that cannot be recovered or converted further. Such waste occupies valuable landfill space, reducing the site's life.

3. Maximize the energy recovery (ER) (in MW h/ year) from MRFs, incinerators, and sanitary landfills

$$
\begin{aligned}
\max \operatorname{ER}(x):= & \sum_{v \in V} \sum_{\rho \in P} A_{v}^{\mathrm{E}} c_{\rho}^{v}+\sum_{\xi \in E} \sum_{\sigma \in D} \Gamma_{\xi}^{\mathrm{E}} d_{\sigma}^{\xi} \\
& +\sum_{o \in O} \sum_{\tau \in T} E_{o}^{\mathrm{E}} e_{\tau}^{o} .
\end{aligned}
$$

4. Maximize the material recovery (MR) (in ton/ year) from MRFs

$$
\max \operatorname{MR}(x):=\sum_{v \in V} \sum_{\rho \in P} A_{v}^{\mathrm{M}} c_{\rho}^{v}+\sum_{\xi \in E} \sum_{\sigma \in D} \Gamma_{\xi}^{\mathrm{M}} d_{\sigma}^{\xi} .
$$

5. Minimize the total cost (TC) (in Euro/day), which includes the installation or opening costs, transportation costs, and treatment costs. Hence, $\min \mathrm{TC}(x):=\operatorname{IC}(x)+\operatorname{Trans} C(x)+$ Treat $C(x)$, where

- installation cost $\operatorname{IC}(x)$ : As installation cost, we consider the investment cost per tonne of waste

$$
\begin{aligned}
\mathrm{IC}(x):= & \sum_{\mu \in M} \sum_{\pi \in \Pi} \mathrm{CFF}_{\varphi \pi}^{\mu} b_{\pi}^{\mu}+\sum_{v \in V} \sum_{\rho \in P} \mathrm{CFF}_{\alpha \rho}^{v} c_{\rho}^{v} \\
& +\sum_{\xi \in E} \sum_{\sigma \in D} \mathrm{CFF}_{\psi \sigma}^{\xi} d_{\sigma}^{\xi}+\sum_{o \in O} \sum_{\tau \in T} \mathrm{CFF}_{\omega \tau}^{o} e_{\tau}^{o},
\end{aligned}
$$

- transportation costs Trans $C(x)$ : In defining the transportation cost, the maximum distance between a waste producer and either a transfer station or sanitary landfill $(25 \mathrm{~km}$, based on the maximum one-way distance of collection trucks in daily trips) and the $100 \mathrm{~km}$ between a transfer station and a landfill are taken into account.

$$
\begin{aligned}
& \operatorname{Trans} C(x):=\sum_{i \in I} \sum_{\mu \in M} \sum_{\pi \in \Pi} \mathrm{CFVtp}_{\alpha, \varphi i \pi}^{\mu} \alpha_{i \pi}^{\mu} \\
& +\sum_{i \in I} \sum_{v \in V} \sum_{\rho \in P} \mathrm{CFVtp}_{\alpha \chi i \rho}^{v} \varepsilon_{i \rho}^{v} \\
& +\sum_{i \in I} \sum_{\xi \in E} \sum_{\sigma \in D} \mathrm{CFVtp}_{\alpha \psi i \sigma}^{\xi} \zeta_{i \sigma}^{\xi} \\
& +\sum_{i \in I} \sum_{o \in O} \sum_{\tau \in T} \mathrm{CFVtp}_{\alpha \omega i \tau}^{. o} \eta_{i \tau}^{o} \\
& +\sum_{\mu \in M} \sum_{\pi \in \Pi} \sum_{v \in V} \sum_{\rho \in P} \mathrm{CFVtp}_{\varphi \chi \lambda \rho}^{\mu v} \varsigma_{\pi \rho}^{\mu v} \\
& +\sum_{\mu \in M} \sum_{\pi \in \Pi} \sum_{\xi \in E} \sum_{\sigma \in D} \mathrm{CFVtp}_{\varphi \psi \pi \sigma}^{\mu \xi} \theta_{\pi \sigma}^{\mu \xi} \\
& +\sum_{\mu \in M} \sum_{\pi \in \Pi} \sum_{o \in O} \sum_{\tau \in T} \mathrm{CFVtp}_{\varphi \omega \pi \tau}^{\mu o} \tau_{\pi \tau}^{\mu o} \\
& +\sum_{v \in V} \sum_{\rho \in P} \sum_{o \in O} \sum_{\tau \in T} \mathrm{CFVtp}_{\chi \omega \rho \tau}^{v o} \kappa_{\rho \tau}^{v o} \\
& +\sum_{\xi \in E} \sum_{\sigma \in D} \sum_{o \in O} \sum_{\tau \in T} \mathrm{CFVtp}_{\psi \omega \sigma \tau}^{\xi o} \delta_{\sigma \tau}^{\xi o},
\end{aligned}
$$

- treatment costs Treat $C(x)$

$$
\begin{aligned}
\text { Treat } C(x): & =\sum_{\mu \in M} \sum_{\pi \in \Pi} \mathrm{CFVtr}_{\varphi \pi}^{\mu} b_{\pi}^{\mu} \\
& +\sum_{v \in V} \sum_{\rho \in P} \mathrm{CFVtr}{ }_{\alpha \rho}^{v} c_{\rho}^{v} \\
& +\sum_{\xi \in E} \sum_{\sigma \in D} \mathrm{CFVtr}_{\psi \sigma}^{\xi} d_{\sigma}^{\xi}+\sum_{o \in O} \sum_{\tau \in T} \mathrm{CFV}_{\omega \tau}^{o} e_{\tau}^{o} .
\end{aligned}
$$


The model includes the following constraints, which construct a feasible set denoted by $X$ :

1. Service demand constraints, i.e., the amount of waste produced at a waste producer is equal to the sum of waste flow to other possible facilities

$$
\begin{aligned}
a_{i}= & \sum_{\mu \in M} \sum_{\pi \in \Pi} \alpha_{i \pi}^{\mu}+\sum_{v \in V} \sum_{\rho \in P} \varepsilon_{i \rho}^{v}+\sum_{\xi \in E} \sum_{\sigma \in D} \zeta_{i \sigma}^{\xi} \\
& +\sum_{o \in O} \sum_{\tau \in T} \eta_{i \tau}^{o} \quad \forall i \in I .
\end{aligned}
$$

2. Mass input-output relation constraints

- No transfer station may keep the waste

$$
\begin{aligned}
b_{\pi}^{\mu}= & \sum_{v \in V} \sum_{\rho \in P} \varsigma_{\pi \rho}^{\mu v}+\sum_{\xi \in E} \sum_{\sigma \in D} \theta_{\pi \sigma}^{\mu \xi}+\sum_{o \in O} \sum_{\tau \in T} l_{\pi \tau}^{\mu o} \\
& \forall \mu \in M, \pi \in \Pi .
\end{aligned}
$$

- Reduction on the output of an MRF and incinerator determined by the mass preservation rate of the MRF and incinerator

$$
\begin{aligned}
& f^{v} c_{\rho}^{v}=\sum_{o \in O} \sum_{\tau \in T} \kappa_{\rho \tau}^{v o} \quad \forall v \in V, \tau \in T, \\
& f^{\xi} d_{\sigma}^{\xi}=\sum_{o \in O} \sum_{\tau \in T} \delta_{\sigma \tau}^{\xi o} \quad \forall \xi \in E, \sigma \in D .
\end{aligned}
$$

3. Minimum amount requirement constraints, which ensure that a facility is opened, only if the minimum amount of waste processed by that facility is available

- Transfer stations: $b_{\pi}^{\mu} \geqslant \underline{k}_{\pi}^{\mu} \varphi_{\pi}^{\mu}, \forall \mu \in M, \pi \in \Pi$.

- MRF facilities: $c_{\rho}^{v} \geqslant \underline{g}_{\rho}^{v} \chi_{\rho}^{v}, \forall v \in V, \rho \in P$.

- Incinerators: $d_{\sigma}^{\xi} \geqslant \underline{h}_{\sigma}^{\xi} \psi_{\sigma}^{\xi}, \forall \xi \in E, \sigma \in D$.

- Landfills: $e_{\tau}^{o} \geqslant \underline{u}_{\tau}^{o} \omega_{\tau}^{o}, \forall o \in O, \tau \in T$.

4. Capacity constraints

- Transfer stations: $b_{\pi}^{\mu} \leqslant \bar{k}_{\pi}^{\mu} \varphi_{\pi}^{\mu}, \forall \mu \in M, \pi \in \Pi$.

- MRF facilities: $c_{\rho}^{v} \leqslant \bar{g}_{\rho}^{v} \chi_{\rho}^{v}, \forall v \in V, \rho \in P$.

- Incinerators: $d_{\sigma}^{\xi} \leqslant \bar{h}_{\sigma}^{\xi} \psi_{\sigma}^{\xi}, \forall \xi \in E, \sigma \in D$.

- Landfills: $e_{\tau}^{o} \leqslant \bar{u}_{\tau}^{o} \omega_{\tau}^{o}, \forall o \in O, \tau \in T$.

5. Constraints on the maximum number of opened facilities

- Transfer stations: $\sum_{\mu \in M} \sum_{\pi \in \Pi} \varphi_{\pi}^{\mu} \leqslant p^{\varphi}$.

- MRFs: $\sum_{v \in V} \sum_{\rho \in P} \chi_{\rho}^{v} \leqslant p^{\chi}$.

- Incinerators: $\sum_{\xi \in E} \sum_{\sigma \in D} \psi_{\sigma}^{\xi} \leqslant p^{\psi}$.

- Landfills: $\sum_{o \in O} \sum_{\tau \in T} \omega_{\tau}^{o} \leqslant p^{\omega}$.

6. Nonnegativity constraints for flow variables and binary variables on location decision variables.

The purpose of the multicriteria model is to find a nondominated solution. In the next section, we provide a brief review of the nondominated solu- tions, and describe how a particular nondominated solution can be generated using this formulation. We are interested in a "fair" solution, where the normalized objective functions are as close to one another as possible.

\section{Lexicographic minimax approach to find a fair solution}

The multiple-objective mathematical programming (MOMP) with $K$ conflicting objectives can be formulated as

$$
\begin{array}{ll}
\text { Min } & f(x)=\left(f_{1}(x), \ldots, f_{K}(x)\right) \\
\text { s.t. } & x \in X \subset R^{n},
\end{array}
$$

where $x$ is an $n$-dimensional vector of decision variables, $X$ is the decision space, and $f(x)$ is a vector of $K$ real-valued functions. The objective (or criterion) space, denoted by $Y$, is defined as $Y:=\{y: y=f(x)$, $x \in X\}$ and $Y \subset R^{K}$. We refer to the elements of the objective space as outcome vectors. In general, there exists no solution that simultaneously optimizes all objectives in MOMP. Instead, we focus on Pareto optimal solutions. If $f_{i}(x) \leqslant f_{i}\left(x^{\prime}\right)$ for all $i=1, \ldots, K$ and $f_{j}(x)<f_{j}\left(x^{\prime}\right)$ for at least one $j$, then we say $x$ dominates $x^{\prime}$. A solution that is not dominated by any other is called Pareto optimal. A Pareto optimal solution cannot be improved in all objectives simultaneously, i.e., $x^{*} \in X$ is Pareto optimal if and only if there exists no $x \in X$ such that $f(x) \leqslant f\left(x^{*}\right)$ and $f(x) \neq f\left(x^{*}\right)$. If $x^{*}$ is a Pareto optimal solution, $f\left(x^{*}\right)$ is called efficient and both $x^{*}$ and $f\left(x^{*}\right)$ are called nondominated. Hence, Pareto optimality is defined in the decision space and efficiency is defined in the objective space.

The concept of a "fair" efficient solution is a refinement of the Pareto optimality. Suppose that all objectives $f_{1}, \ldots, f_{K}$ are in the same scale (if not, a priori normalization should be applied). A feasible solution $x \in X$ is called the minimax solution of the MOMP (1) with $K$ objectives, if it is an optimal solution to the problem

$\min _{x}\left\{\max _{i=1, \ldots, K} f_{i}(x): x \in X\right\}$.

Hence, the minimax solution is the solution that minimizes the worst objective value. Moreover, the minimax solution is regarded as maintaining equity as described by the following theorem (the maximin version of this theorem appeared in [21]). 
Theorem 1. If there exists an efficient outcome vector $\bar{y} \in Y$ with perfect equity $\bar{y}_{1}=\bar{y}_{2}=\cdots=\bar{y}_{K}$, then $\bar{y}$ is the unique optimal solution of the minimax problem

$\min \left\{\max _{i=1, \ldots, K} y_{i}: y \in Y\right\}$.

The optimal set of the minimax problem (2) always contains an efficient solution of the original multiple criteria problem (1). However, if the optimal solution is not unique, some of them may not be efficient (see e.g. [20]). This is of course a disadvantage, despite of the equity property of the minimax solution. To resolve this problem, a refinement technique is needed to guarantee that only efficient solutions are selected in case there are multiple optimal minimax solutions. We discuss in the following a lexicographic minimax problem as a refinement of this minimax problem.

If we consider minimizing also the second worst objective value, the third worst objective value, and so on, then we will obtain a lexicographic mini$\max$ solution. Let $a=\left(a_{1}, a_{2}, \ldots, a_{K}\right)$ and $b=\left(b_{1}, b_{2}, \ldots, b_{K}\right)$ be two $K$-vectors. We say vector $a$ is lexicographically smaller than $b, a<_{\operatorname{lex}} b$, if there is index $j \in\{1, \ldots, K-1\}$ such that $a_{i}=b_{i}$ for all $i \leqslant j$ and $a_{j+1}<b_{j+1}$. And we say $a$ is lexicographically smaller or equal $b, a \leqslant_{\operatorname{lex}} b$, if $a<_{\operatorname{lex}} b$ or $a=b$. Furthermore, let $\Theta: R^{K} \rightarrow R^{K}$ a map which orders the components of vectors in a nonincreasing order, i.e., $\Theta\left(y_{1}, y_{2}, \ldots, y_{K}\right)=\left(y_{\langle 1\rangle}, y_{\langle 2\rangle}, \ldots, y_{\langle K\rangle}\right)$ with $y_{\langle 1\rangle} \geqslant y_{\langle 2\rangle} \geqslant \cdots \geqslant y_{\langle K\rangle}$, where $y_{\langle i\rangle}$ denotes the $i$ th component of $\Theta(y)$. The lexicographic minimax problem is formalized as

lex $\min _{x}\left\{\Theta\left(f_{1}(x), \ldots, f_{K}(x)\right): x \in X\right\}$.

A feasible solution $x \in X$ is a lexicographic minimax solution if its outcome vector is lexicographically minimal with respect to $\Theta(f(x))$, i.e.,

$$
\begin{aligned}
& \Theta\left(f_{1}(x), \ldots, f_{K}(x)\right) \leqslant \operatorname{lex} \Theta\left(f_{1}\left(x^{\prime}\right), \ldots, f_{K}\left(x^{\prime}\right)\right), \\
& \quad x^{\prime} \in X .
\end{aligned}
$$

In the following we state some properties of the lexicographic minimax problem (see [7] for the proofs):

(a) The lexicographic minimax solution is an efficient solution of the MOMP (1).

(b) Every lexicographic minimax solution is also an optimal solution of the minimax problem.

(c) The value of a lexicographic minimax solution is uniquely defined. (d) The numbering of objective is irrelevant for the lexicographic minimax solution, i.e., if $f_{\pi}(x):=\left(f_{\pi(1)}(x), \ldots, f_{\pi(K)}(x)\right)$ with $\pi$ a permutation of $\{1, \ldots, K\}$, then the set of lexicographic minimax solution with respect to an objective vector $f$ is the same as that with respect to the objective vector $f_{\pi}$.

(e) The set of lexicographic minimax solutions is invariant under monotone transformations.

Property (b) together with Theorem 1 guarantees that the lexicographic minimax model generates efficient solutions with perfect equity, whenever such an efficient solution exists. Property (c) implies that all optimal solutions have the same $\Theta$-objective values, but the order might be different. For example, $y^{\prime}=(4,1,2)$ and $y^{\prime \prime}=(2,4,1)$ have different order but $\Theta\left(y^{\prime}\right)=\Theta\left(y^{\prime \prime}\right)=(4,2,1)$. Moreover, the set of lexicographic minimax solutions itself might be large. This property enables us to present some alternative solutions to the DMs without worrying about the differences in the objective values. Properties (d) and (e) suggest that the lexicographic minimax approach is an appropriate tool when the decision maker is totally indifferent to the criteria and the performance is measured at least on ordinal scale [7]. The multiobjective problem (1), therefore, is replaced with the lexicographic minimization problem (4).

The concept of lexicographic minimax solution is known in the game theory as the nucleolus of a matrix game. The solution concept of the lexicographic minimax is a refinement of the minimax solution concept. Therefore, a natural idea to solve the lexicographic minimax problem is to identify all the minimax solutions and to sort their objective value vector in a nonincreasing order to find the lexicographically minimal one (see [7] for discrete problems). For the case of multiobjective linear programming, one can use the sequential optimization with elimination of the dominating functions ([16,17,21] for the lexicographic maximin). This method depends heavily on the convexity of the feasible set. Ogryczak et al. [21] proposed a formulation that transfers any lexicographic maximin problem (either convex or nonconvex) to a lexicographic maximization problem. Following this idea, we now describe how to transfer any lexicographic minimax problem (either convex or nonconvex) to a lexicographic minimization problem. We define an aggregated criterion $\vartheta_{i}(y)=\sum_{j=1}^{i} y_{\langle j\rangle}$ expressing the total of the $i$-worst (the largest) outcomes. For 
a given outcome vector $y, \vartheta_{i}(y)$ for $i=1, \ldots, K$, can be found as the optimal value of the following integer programming (IP) problem:

$\vartheta_{i}(y)=\max \sum_{j=1}^{K} y_{j} u_{i j}$

s.t. $\quad \sum_{j=1}^{K} u_{i j}=i$

$$
u_{i j} \in\{0,1\}, \quad j=1, \ldots, K .
$$

Since the coefficient matrix of $(6)$ is totally unimodular, we can relax $(7)$ to $0 \leqslant u_{i j} \leqslant 1$ that results an LP formulation for a given outcome vector $y$. This problem becomes nonlinear when $y$ is considered as a variable. To overcome this difficulty, we can use the dual formulation of the LP version of (5) (7) as follows:

$\vartheta_{i}(y)=\min i \lambda_{i}+\sum_{j=1}^{K} d_{i j}$

s.t. $\quad \lambda_{i}+d_{i j} \geqslant y_{j}, \quad j=1, \ldots, K$,

$$
d_{i j} \geqslant 0, \quad j=1, \ldots, K \text {. }
$$

Consequently, we obtain

$$
\begin{aligned}
\vartheta_{i}(f(x))= & \min \left\{i \lambda_{i}+\sum_{j=1}^{K} d_{i j}: x \in X, \lambda_{i}+d_{i j}\right. \\
& \left.\geqslant f_{j}(x), d_{i j} \geqslant 0, j=1, \ldots, K\right\},
\end{aligned}
$$

which can be re-formulated as

$$
\begin{aligned}
\overline{\vartheta_{i}}(f(x))= & \min \left\{\lambda_{i}+\frac{1}{i} \sum_{j=1}^{K} d_{i j}: x \in X, \lambda_{i}+d_{i j}\right. \\
& \left.\geqslant f_{j}(x), d_{i j} \geqslant 0, j=1, \ldots, K\right\},
\end{aligned}
$$

where $\overline{\vartheta_{i}}(f(x)):=\frac{\vartheta_{i}(f(x))}{i}$ can be interpreted as the worst conditional means [21]. Furthermore, for any two vectors $y^{\prime}, y^{\prime \prime} \in Y$ one can easily show that $\Theta\left(y^{\prime}\right) \leqslant \operatorname{lex} \Theta\left(y^{\prime \prime}\right)$ if and only if $\left(\bar{\vartheta}_{1}\left(y^{\prime}\right), \ldots, \bar{\vartheta}_{K}\left(y^{\prime}\right)\right)$

$$
\leqslant_{\operatorname{lex}}\left(\bar{\vartheta}_{1}\left(y^{\prime \prime}\right), \ldots, \bar{\vartheta}_{K}\left(y^{\prime \prime}\right)\right) .
$$

Consequently, the following assertion is valid.

Theorem 2. A feasible vector $x \in X$ is an optimal solution of problem (4) if and only if it is the optimal solution of the aggregated lexicographic problem

$\operatorname{lex} \min \left\{\left(\bar{\vartheta}_{1}(f(x)), \ldots, \bar{\vartheta}_{K}(f(x))\right): x \in X\right\}$.

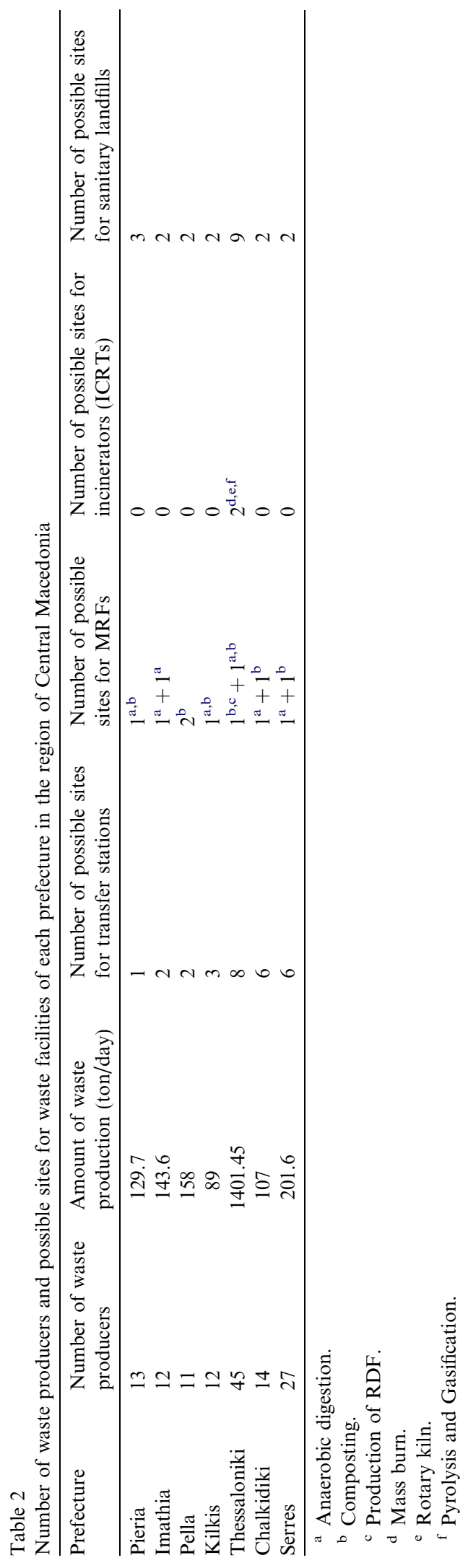


Following Theorem 2, the lexicographic minimax problem (4) can be solved as a lexicographic minimization problem with linear objectives

$$
\begin{aligned}
& \operatorname{lex} \min \left\{\left(\lambda_{1}+\sum_{j=1}^{K} d_{1 j}, \ldots, \lambda_{K}+\frac{1}{K} \sum_{j=1}^{K} d_{K j}\right)\right. \\
& \left.: x \in X, \lambda_{i}+d_{i j} \geqslant f_{j}(x), d_{i j} \geqslant 0, i, j=1, \ldots, K\right\} .
\end{aligned}
$$

This formulation is valid either for convex or nonconvex $X$.

Despite of its interesting properties, there are only a few applications of lexicographic minimax (or lexicographic maximin) approach. It originated in game theory in early 60s, which has been later refined to the formal nucleolus definition (see the review in [18]). This approach has been generalized to an arbitrary number of objective functions [24] and used for linear programming problems related to multiperiod resource allocation [16], for linear multiple criteria problems [18], and for discrete problems $[7,8]$. The lexicographic minimax turns out to be a special case of the so-called ordered weighted averaging (OWA) aggregation for the multicriteria problems, introduced by Yager in late $80 \mathrm{~s}$ (see $[21,26]$ ). Furthermore, the fairness concept of the lexicographic minimax has been investigated in [18] and used for several applications such as equitable resource allocation problems [16] and telecommunication network design [21-23].

\section{MSW planning in the Central Macedonia region}

In this section, we contrast regional and prefectural solid waste management planning. In the prefectural planning (Section 6.1), we look for the optimal location and allocation decision of waste facilities per prefecture taking into account the five objectives discussed in Section 4. In contrast, in the regional planning (Section 6.2), we unite all prefectures in the region of Central Macedonia and look for the optimal location and allocation decision of waste facilities that cover the needs of all seven prefectures in this region.

\subsection{Prefectural planning}

The number of waste producers and possible sites for waste facilities are different for each prefecture, as shown in Table 2. The maximum distance between a waste producer and a destination facility (transfer station or landfill) should be $25 \mathrm{~km}$. This distance limit, however, can be increased when transportation of waste takes place among transfer stations and material recovery facilities or incinerators, because such facilities cannot be densely placed in one area. There are already two transfer stations in the south east of the Greater Thessaloniki area and in Nea Michaniona, in the prefecture of Thessaloniki. Moreover, to avoid social problems, we stipulate that there should be no more than two sanitary landfills in each prefecture.

By multiplying all maximization objective functions by -1 , we get the following multiobjective minimization model:

\section{$\operatorname{Min}\left(f_{1}(x), f_{2}(x), f_{3}(x), f_{4}(x), f_{5}(x)\right)$}

s.t. $x \in X$,

where $f_{1}, f_{2}, f_{3}, f_{4}, f_{5}$ associate with GHE, FIDI, ER, MR, and TC, respectively. To avoid dimensional inconsistency among various objectives, we scale the values of GHE, FIDI, ER, MR, and TC into the interval $[0,1]$. We define $\overline{f_{1}}, \overline{f_{2}}, \overline{f_{3}}, \overline{f_{4}}, \overline{f_{5}}$ as the normalized objective functions of GHE, FIDI, ER, MR, and TC, respectively. We define $\bar{f}_{i}(x):=$ $\frac{f_{i}(x)-f_{i}^{\min }}{f_{i}^{\max }-f_{i}^{\min }}$ if the original objective $f_{i}(x)$ is minimization and $\bar{f}_{i}(x):=\frac{f_{i}^{\max }-f_{i}(x)}{f_{i}^{\max }-f_{i}^{\min }}$ otherwise, where $f_{i}^{\max }$ and $f_{i}^{\min }$

Table 3

\begin{tabular}{|c|c|c|c|c|c|c|c|c|c|c|}
\hline \multirow[t]{2}{*}{ Prefecture } & \multicolumn{2}{|l|}{ GHE } & \multicolumn{2}{|l|}{ FIDI } & \multicolumn{2}{|l|}{ ER } & \multicolumn{2}{|l|}{ MR } & \multicolumn{2}{|l|}{$\mathrm{TC}$} \\
\hline & $f_{1}^{\min }$ & $f_{1}^{\max }$ & $f_{2}^{\min }$ & $f_{2}^{\max }$ & $f_{3}^{\min }$ & $f_{3}^{\max }$ & $f_{4}^{\min }$ & $f_{4}^{\max }$ & $f_{5}^{\min }$ & $f_{5}^{\max }$ \\
\hline Pieria & 821.286 & 1592.72 & 58.18 & 129.7 & 2855.78 & 7490.69 & 0 & 14,304 & 593.09 & $13,097.2$ \\
\hline Imathia & 705.363 & 1763.41 & 57.44 & 143.6 & 2452.69 & 8118.61 & 0 & 14,556 & 1883.84 & $15,549.7$ \\
\hline Pella & 775.605 & 1939.01 & 63.16 & 157.9 & 2696.93 & 6742.33 & 0 & 4737 & 3229.52 & $13,776.8$ \\
\hline Kilkis & 1092.92 & 1092.92 & 89 & 89 & 3800.3 & 3800.3 & 0 & 0 & 1175.32 & 3063.07 \\
\hline Thessaloniki & 6955.39 & 132,213 & 566.4 & 1401.45 & $24,185.3$ & 186,603 & 0 & 167,010 & $55,037.1$ & 203,660 \\
\hline Chalkidiki & 525.584 & 1313.96 & 42.8 & 107 & 1827.56 & 6249.49 & 0 & 12,312 & 2173.93 & $14,469.3$ \\
\hline Serres & 1109.62 & 2475.65 & 90.36 & 201.6 & 3858.37 & $11,645.2$ & 0 & 22,248 & 3213.66 & $24,456.9$ \\
\hline
\end{tabular}

Optimal values obtained by individual optimization of the objectives for each prefecture 
Table 4

Optimal solutions obtained by individual optimization for each prefecture in the region of Central Macedonia

\begin{tabular}{|c|c|c|c|c|c|c|}
\hline & & GHE (min) & FIDI (min) & $\mathrm{ER}(\max )$ & MR (max) & $\mathrm{TC}(\min )$ \\
\hline \multicolumn{2}{|c|}{ Objective value (in total) } & $11,985.77$ & 967.34 & $230,649.6$ & 235,167 & $67,306.46$ \\
\hline $\begin{array}{l}\text { Objective } \\
\text { value }\end{array}$ & $\begin{array}{l}\text { Pieria } \\
\text { Imathia } \\
\text { Pella } \\
\text { Kilkis } \\
\text { Thessaloniki } \\
\text { Chalkidiki } \\
\text { Serres }\end{array}$ & $\begin{array}{l}821.286 \\
705.363 \\
775.605 \\
1092.92 \\
6955.39 \\
525.584 \\
1109.62\end{array}$ & $\begin{array}{l}58.18 \\
57.44 \\
63.16 \\
89 \\
566.4 \\
42.8 \\
90.36\end{array}$ & $\begin{array}{l}7,490.69 \\
8,118.61 \\
6742.33 \\
3800.3 \\
186,603 \\
6249.49 \\
11,645.2\end{array}$ & $\begin{array}{l}14,304 \\
14,556 \\
4737 \\
0 \\
167,010 \\
12,312 \\
22,248\end{array}$ & $\begin{array}{l}593.09 \\
1883.84 \\
3229.52 \\
1175.32 \\
55,037.1 \\
2173.93 \\
3213.66\end{array}$ \\
\hline $\begin{array}{l}\text { Transfer } \\
\text { station }\end{array}$ & $\begin{array}{l}\text { Pieria } \\
\text { Imathia } \\
\text { Pella } \\
\text { Kilkis } \\
\text { Thessaloniki }\end{array}$ & $\begin{array}{l}\text { Anatolikos Olympos } \\
\text { Andigonides (Kavasila), } \\
\text { Macedonia (Rizomata) } \\
\text { Edessa, Exaplatanos, } \\
\text { Leianovergi } \\
\text { Livadia, Mouriai, } \\
\text { Polikastro } \\
\text { Agios Athanasios } \\
\text { (Gefira), Nea Michaniona, } \\
\text { Profitis, SE GTA, Sindos, } \\
\text { Vrasna, West GTA } \\
\text { Arnea, Stageira (Ierisos), } \\
\text { Nea Kalliktratia, Nea } \\
\text { Moudania, Nikitas } \\
\text { Sithonia, Toroni (Sikia) } \\
\text { Achinos, Achladochori, } \\
\text { Alistrati, Amfipolis, Ano } \\
\text { Vrondou, Neo Petritsi }\end{array}$ & $\begin{array}{l}\text { Anatolikos Olympos } \\
\text { Andigonides (Kavasila), } \\
\text { Macedonia (Rizomata) } \\
\text { Edessa, Exaplatanos, } \\
\text { Leianovergi } \\
\text { Livadia, Mouriai, } \\
\text { Polikastro } \\
\text { Agios Athanasios } \\
\text { (Gefira), Nea Michaniona, } \\
\text { Profitis, SE GTA, Sindos, } \\
\text { Vrasna, West GTA } \\
\text { Arnea, Stageira (Ierisos), } \\
\text { Nea Kalliktratia, Nea } \\
\text { Moudania, Nikitas } \\
\text { Sithonia, Toroni (Sikia) } \\
\text { Achinos, Achladochori, } \\
\text { Alistrati, Amfipolis, Ano } \\
\text { Vrondou, Neo Petritsi }\end{array}$ & $\begin{array}{l}\text { Anatolikos Olympos } \\
\text { Andigonides (Kavasila), } \\
\text { Macedonia (Rizomata) } \\
\text { Edessa, Exaplatanos, } \\
\text { Leianovergi } \\
\text { Livadia, Mouriai, } \\
\text { Polikastro } \\
\text { Agios Athanasios } \\
\text { (Gefira), Nea Michaniona, } \\
\text { Profitis, SE GTA, Sindos, } \\
\text { Vrasna, West GTA } \\
\text { Arnea, Stageira (Ierisos), } \\
\text { Nea Kalliktratia, Nea } \\
\text { Moudania, Nikitas } \\
\text { Sithonia, Toroni (Sikia) } \\
\text { Achinos, Achladochori, } \\
\text { Alistrati, Amfipolis, Ano } \\
\text { Vrondou, Neo Petritsi }\end{array}$ & $\begin{array}{l}\text { Anatolikos Olympos } \\
\text { Andigonides (Kavasila), } \\
\text { Macedonia (Rizomata) } \\
\text { Edessa, Exaplatanos, } \\
\text { Leianovergi } \\
\text { Livadia, Mouriai, } \\
\text { Polikastro } \\
\text { Agios Athanasios } \\
\text { (Gefira), Nea Michaniona, } \\
\text { Profitis, SE GTA, Sindos, } \\
\text { Vrasna, West GTA } \\
\text { Arnea, Stageira (Ierisos), } \\
\text { Nea Kalliktratia, Nea } \\
\text { Moudania, Nikitas } \\
\text { Sithonia, Toroni (Sikia) } \\
\text { Achinos, Achladochori, } \\
\text { Alistrati, Amfipolis, Ano } \\
\text { Vrondou, Neo Petritsi }\end{array}$ & $\begin{array}{l}\text { Anatolikos Olympos } \\
\text { Andigonides (Kavasila), } \\
\text { Macedonia (Rizomata) } \\
\text { Edessa, Exaplatanos, } \\
\text { Leianovergi } \\
\text { Livadia, Mouriai, } \\
\text { Polikastro } \\
\text { Agios Athanasios } \\
\text { (Gefira), Nea Michaniona, } \\
\text { Profitis, SE GTA, Sindos, } \\
\text { Vrasna, West GTA } \\
\text { Arnea, Stageira (Ierisos), } \\
\text { Nea Kalliktratia, Nea } \\
\text { Moudania, Nikitas } \\
\text { Sithonia, Toroni (Sikia) } \\
\text { Achinos, Achladochori, } \\
\text { Alistrati, Amfipolis, Ano } \\
\text { Vrondou, Neo Petritsi }\end{array}$ \\
\hline MRF & $\begin{array}{l}\text { Pieria } \\
\text { Imathia } \\
\text { Pella } \\
\text { Kilkis } \\
\text { Thessaloniki } \\
\text { Chalkidiki } \\
\text { Serres }\end{array}$ & $\begin{array}{l}\text { Katerini }^{\text {b }} \\
\text { Veroia }^{\mathrm{b}} \\
\text { Pella }^{\mathrm{b}} \\
\text { Sindos IA } \\
\text { Poligiros }^{\mathrm{b}} \text {, Thermi IA } \\
\text { Serres }^{\mathrm{b}, \mathrm{c}}\end{array}$ & $\begin{array}{l}\text { Katerinia }^{\mathrm{a}} \\
\text { Veroia }^{\mathrm{b}} \\
\text { Pella }^{\mathrm{b}} \\
\text { Sindos IA }^{\mathrm{b}} \text {, Thermi IA } \\
\text { Poligiros } \\
\text { Serres }^{\mathrm{b}}\end{array}$ & $\begin{array}{l}\text { Katerini }^{\mathrm{a}} \\
\text { Meliki }^{\mathrm{a}} \\
- \\
- \\
\text { Kassandria }^{\mathrm{a}} \\
\text { Zevgolation }^{\mathrm{a}}\end{array}$ & $\begin{array}{l}\text { Katerini }^{\mathrm{a}} \\
\text { Meliki }^{\mathrm{a}} \\
\text { Giannitsa }^{\mathrm{b}} \\
\text { Thermi IA }^{\mathrm{a}} \\
\text { Kassandria }^{\mathrm{a}} \\
\text { Zevgolation }^{\mathrm{a}}\end{array}$ & $\begin{array}{l}- \\
- \\
-\end{array}$ \\
\hline ICRT & $\begin{array}{l}\text { Thessaloniki } \\
\text { Other than }\end{array}$ & - & $\operatorname{Sindos}_{-} \mathrm{IA}^{\mathrm{d}, \mathrm{e}}$ & ${\operatorname{Sindos~} \mathrm{IA}^{\mathrm{d}}}_{-}$ & $\begin{array}{l}- \\
-\end{array}$ & - \\
\hline
\end{tabular}




\begin{tabular}{|c|c|c|c|c|c|c|}
\hline \multirow{7}{*}{$\begin{array}{l}\text { Sanitary } \\
\text { Landfill }\end{array}$} & Pieria & Katerini, Kolindros & Kolindros & Kolindros, Litohoro & Kolindros & Katerini, Kolindros \\
\hline & Imathia & Makrochorion & Makrochorion & Makrochorion, Meliki & Makrochorion & Makrochorion, Meliki \\
\hline & Pella & Giannitsa & Giannitsa & Pella, Giannitsa & Pella, Giannitsa & Pella, Giannitsa \\
\hline & Kilkis & Axioupoli, Kilkis & Axioupoli, Kilkis & Axioupoli, Kilkis & Axioupoli, Kilkis & Axioupoli, Kilkis \\
\hline & Thessaloniki & $\begin{array}{l}\text { Agios Antonios, } \\
\text { Mavrorachi }\end{array}$ & $\begin{array}{l}\text { Agios Antonios, } \\
\text { Mavrorachi }\end{array}$ & Mavrorachi, Scholari & Langadas & Koufalia, Mavrorachi \\
\hline & Chalkidiki & Poligiros & Poligiros & Poligiros & Poligiros & Kassandria, Poligiros \\
\hline & Serres & Serres & Serres & Zevgolation & Serres & Serres, Zevgolation \\
\hline
\end{tabular}

${ }^{+}$Rotary kiln.

a Anaerobic digestion.

b Composting.

c Production of RDF.

${ }^{d}$ Mass burn.

e Pyrolysis and Gasification.

Table 5

Optimal values of model (21) at iteration 5 for each prefecture

\begin{tabular}{|c|c|c|c|c|c|c|c|c|}
\hline & & Pieria & Imathia & Pella & Kilkis & Thessaloniki & Chalkidiki & Serres \\
\hline \multirow{5}{*}{$\overline{\lambda_{i}+\frac{1}{i} \sum_{j=1}^{5} d_{i j}}$} & $i=1$ & 0.703877 & 0.680958 & 0.50665 & - & 0.500701 & 0.789614 & 0.54864 \\
\hline & $i=2$ & 0.527138 & 0.603665 & 0.5 & - & 0.500701 & 0.576989 & 0.54864 \\
\hline & $i=3$ & 0.433081 & 0.526863 & 0.497784 & - & 0.500701 & 0.437619 & 0.500002 \\
\hline & $i=4$ & 0.386052 & 0.459657 & 0.496675 & - & 0.462996 & 0.358916 & 0.475684 \\
\hline & $i=5$ & 0.329481 & 0.385823 & 0.488371 & - & 0.377118 & 0.296468 & 0.41196 \\
\hline \multirow{5}{*}{$\bar{f}_{j}\left(x^{5}\right)$} & $j=1$ & 0.350399 & 0.526371 & 0.493351 & 0 & 0.033602 & 0.364364 & 0.54864 \\
\hline & $j=2$ & 0.244966 & 0.373259 & 0.49335 & 0 & 0.349882 & 0.158879 & 0.402727 \\
\hline & $j=3$ & 0.103195 & 0.090487 & 0.50665 & 1 & 0.500701 & 0.0466742 & 0.157067 \\
\hline & $j=4$ & 0.244966 & 0.258038 & 0.49335 & 1 & 0.500701 & 0.122807 & 0.402727 \\
\hline & $j=5$ & 0.703877 & 0.680958 & 0.455154 & 0 & 0.500701 & 0.789614 & 0.54864 \\
\hline
\end{tabular}


Table 6

Fair locations for MSW facilities in each prefecture in the region of Central Macedonia

\begin{tabular}{|c|c|c|c|c|c|c|c|c|}
\hline \multirow[t]{2}{*}{ Waste facilities } & \multicolumn{8}{|l|}{ Prefecture } \\
\hline & Pieria & Imathia & Pella & Kilkis & Thessaloniki & Chalkidiki & Serres & $\begin{array}{l}\text { Sum over all } \\
\text { prefectures }\end{array}$ \\
\hline \#WP & 13 & 12 & 11 & 12 & 45 & 14 & 27 & 134 \\
\hline $\begin{array}{l}\text { Transfer } \\
\text { station }\end{array}$ & $\begin{array}{l}\text { Anatolikos } \\
\text { Olympos }\end{array}$ & $\begin{array}{l}\text { Andigonides } \\
\text { (Kavasila), } \\
\text { Macedonia } \\
\text { (Rizomata) }\end{array}$ & $\begin{array}{l}\text { Edessa, } \\
\text { Exaplatanos, } \\
\text { Leianovergi }\end{array}$ & $\begin{array}{l}\text { Livadia, } \\
\text { Mouriai, } \\
\text { Polikastro }\end{array}$ & $\begin{array}{l}\text { Agios Athanasios } \\
\text { (Gefira), Nea } \\
\text { Michaniona, Profitis, } \\
\text { SE GTA, Sindos, } \\
\text { Vrasna, West GTA }\end{array}$ & $\begin{array}{l}\text { Arnea, Stageira } \\
\text { (Ierisos), Nea } \\
\text { Kalliktratia, Nea } \\
\text { Moudania, Nikitas } \\
\text { Sithonia, Toroni (Sikia) }\end{array}$ & $\begin{array}{l}\text { Achinos, } \\
\text { Achladochori, } \\
\text { Alistrati, } \\
\text { Amfipolis, Ano } \\
\text { Vrondou, Neo } \\
\text { Petritsi }\end{array}$ & $28 \mathrm{TSs}$ \\
\hline MRF & Katerini $^{\mathrm{a}}$ & Meliki $^{\mathrm{a}}$ & Giannitsa $^{\mathrm{b}}$ & & Thermi $\mathrm{IA}^{\mathrm{a}, \mathrm{c}}$ & Kasandria $^{a}$ & Zevgolation $^{\mathrm{a}}$ & 7 MRFs \\
\hline ICRT & - & - & - & - & - & - & - & 0 ICRT \\
\hline $\begin{array}{l}\text { Sanitary } \\
\text { Landfill }\end{array}$ & $\begin{array}{l}\text { Kolindros, } \\
\text { Litohoro }\end{array}$ & $\begin{array}{l}\text { Makrochorion, } \\
\text { Meliki }\end{array}$ & $\begin{array}{l}\text { Pella, } \\
\text { Giannitsa }\end{array}$ & $\begin{array}{l}\text { Axioupoli, } \\
\text { Kilkis }\end{array}$ & $\begin{array}{l}\text { Agios Antonios, } \\
\text { Langadas }\end{array}$ & Poligiros & Serres, Zevgolation & $13 \mathrm{SLs}$ \\
\hline $\operatorname{GHE}\left(\bar{f}_{1}\left(x^{5}\right)\right)$ & $\begin{array}{l}1091.6 \\
(0.350399)\end{array}$ & $\begin{array}{l}1262.29 \\
(0.526371)\end{array}$ & $\begin{array}{l}1349.57 \\
(0.493351)\end{array}$ & $1092.92(0)$ & $11,164.3(0.0336024)$ & $812.84(0.364364)$ & $1859.08(0.54864)$ & $18,632.60$ \\
\hline $\operatorname{FIDI}\left(\bar{f}_{2}\left(x^{5}\right)\right)$ & $\begin{array}{l}75.7 \\
(0.244966)\end{array}$ & $89.6(0.373259)$ & $\begin{array}{l}109.9 \\
(0.49335)\end{array}$ & $89(0)$ & $858.569(0.349882)$ & $53(0.158879)$ & $135.159(0.402727)$ & 1410.93 \\
\hline $\operatorname{ER}\left(\bar{f}_{3}\left(x^{5}\right)\right)$ & $\begin{array}{l}7012.39 \\
(0.103195)\end{array}$ & $\begin{array}{l}7605.92 \\
(0.090487)\end{array}$ & $\begin{array}{l}4692.73 \\
(0.50665)\end{array}$ & $3800.3(1)$ & $105,280(0.500701)$ & $6043.1(0.0466742)$ & $10,422.1(0.157067)$ & $144,856.54$ \\
\hline $\operatorname{MR}\left(\bar{f}_{4}\left(x^{5}\right)\right)$ & $\begin{array}{l}10,800 \\
(0.244966)\end{array}$ & $\begin{array}{l}10,800 \\
(0.258038)\end{array}$ & $2400(0.49335)$ & $0(1)$ & $83,387.9(0.500701)$ & $10,800(0.122807)$ & $13,288.1(0.402727)$ & $131,476.00$ \\
\hline $\mathrm{TC}\left(\bar{f}_{5}\left(x^{5}\right)\right)$ & $\begin{array}{l}9394.45 \\
(0.703877)\end{array}$ & $\begin{array}{l}11,189.7 \\
(0.680958)\end{array}$ & $\begin{array}{l}8030.15 \\
(0.455154)\end{array}$ & $1175.32(0)$ & $129,453(0.500701)$ & $11,882.5(0.789614)$ & $14,868.6(0.54864)$ & $185,993.72$ \\
\hline
\end{tabular}

${ }^{+}$Mass burn; ${ }^{++}$rotary kiln; ${ }^{+++}$pyrolysis and gasification.

a Anaerobic digestion.

b Composting.

c Production of RDF. 
Table 7

Fair waste flow distributions for each prefecture in the region of Central Macedonia

\begin{tabular}{|c|c|c|c|c|c|c|c|c|}
\hline \multirow[t]{2}{*}{ Waste flow } & \multicolumn{8}{|c|}{ Prefecture } \\
\hline & Pieria & Imathia & Pella & Kilkis & Thessaloniki & Chalkidiki & Serres & Sum over all prefectures \\
\hline WP-TS & 0 & 16.3 & 66.2 & 16.5 & 449.349 & 70.6 & 65 & 683.949 \\
\hline WP-MRF ${ }^{a}$ & 90 & 73.7 & 0 & 0 & 345.062 & 23.8 & 45.7344 & 578.2964 \\
\hline $\mathrm{WP}-\mathrm{MRF}^{\mathrm{b}}$ & 0 & 0 & 80 & 0 & 0 & 0 & 0 & 80 \\
\hline $\mathrm{WP}-\mathrm{MRF}^{\mathrm{c}}$ & 0 & 0 & 0 & 0 & 559.739 & 0 & 0 & 559.739 \\
\hline WP-ICRT & 0 & 0 & 0 & 0 & 0 & 0 & 0 & 0 \\
\hline WP-SL & 39.7 & 53.6 & 11.7 & 72.5 & 47.3 & 12.6 & 90.8656 & 328.2656 \\
\hline $\mathrm{TS}-\mathrm{MRF}^{\mathrm{a}}$ & 0 & 16.3 & 0 & 0 & 0 & 66.2 & 65 & 147.5 \\
\hline $\mathrm{TS}^{-\mathrm{MRF}^{\mathrm{b}}}$ & 0 & 0 & 0 & 0 & 0 & 0 & 0 & 0 \\
\hline $\mathrm{TS}_{\mathrm{MRF}}^{\mathrm{c}}$ & 0 & 0 & 0 & 0 & 0 & 0 & 0 & 0 \\
\hline TS-ICRT & 0 & 0 & 0 & 0 & 0 & 0 & 0 & 0 \\
\hline TS-SL & 0 & 0 & 66.2 & 16.5 & 449.349 & 4.4 & 0 & 536.449 \\
\hline $\mathrm{MRF}^{\mathrm{a}}-\mathrm{SL}$ & 36 & 36 & 0 & 0 & 138.025 & 36 & 44.2938 & 290.3188 \\
\hline $\mathrm{MRF}^{\mathrm{b}}-\mathrm{SL}$ & 0 & 0 & 32 & 0 & 0 & 0 & 0 & 32 \\
\hline $\mathrm{MRF}^{\mathrm{c}}-\mathrm{SL}$ & 0 & 0 & 0 & 0 & 223.896 & 0 & 0 & 223.896 \\
\hline ICRT-SL & 0 & 0 & 0 & 0 & 0 & 0 & 0 & 0 \\
\hline
\end{tabular}

a Anaerobic digestion.

${ }^{\mathrm{b}}$ Composting.

${ }^{c}$ Production of RDF.

are the minimum and the maximum value of $f_{i}(x)$, respectively. Table 3 summarizes $f_{i}^{\max }$ and $f_{i}^{\min }$ of all prefectures and Table 4 gives the optimal solutions obtained by individual optimization of the objectives for each prefecture. Table 2 shows that there is no incinerator location in Kilkis. Moreover, the minimum capacity of MRF facilities (composting and anaerobic digestion) in Kilkis exceeds the waste supply. Therefore, no MRF facility is considered in a feasible solution for this prefecture. Consequently, the only source of the greenhouse effect and energy recovery is the sanitary landfill. As we have only sanitary landfill and transfer station, the values of greenhouse effect, energy recovery, and final disposal are the same for every feasible solution as shown in Table 3. Moreover, since material recovery is contributed only by the MRF facility, its value is always zero. Hence we can consider a single objective, namely minimizing the total cost, for this prefecture.

Now, we implement (14) with objective functions $\bar{f}_{i}(x), i=1, \ldots, K:=5$ for each prefecture to obtain a fair solution. We use CPLEX 8.1 to solve the mixed-integer linear programming problem.

In Table 5, we summarize the results for each prefecture (we show only the optimal objective values and $\bar{f}_{i}(x)$ for iteration 5$)$. Note that it is not necessary to implement (14) for Kilkis since it has a single objective to be minimized. There is no prefecture which has normalized objective functions satisfying perfect equity $\bar{f}_{1}(x)=\cdots=\bar{f}_{5}(x)$. However,
Pella has nearly perfect equity. The fair solutions for each prefecture are summarized in Tables 6 and 7. In total, $63.3 \%$ (see Table 7) of waste goes to the final disposal at the sanitary landfills while $23.3 \%$ of it goes directly from the waste producers. Moreover, building an incinerator (of any type) is not recommended.

\subsection{Regional planning}

In the regional planning, we unite all prefectures in Central Macedonia and look for the optimal location and allocation decision of waste facilities that cover the needs of all seven prefectures in this region. Therefore, we have 134 waste producers with a total of 2230 tonnes of waste per day, 29 possible sites for locating transfer stations, 9 possible sites for locating material recovery facilities, 6 possible sites for locating incinerators, and 22 possible sites for locating sanitary landfills. Moreover, there should be, at most, 14 opened sanitary landfills. This combination implies that the mixed-integer programming model (in Section 4) has 337 constraints and 942 variables with 73 binaries among them. Each linear programming problem in each iterative process can be solved by using CPLEX 8.1. Table 8 gives the optimal solutions obtained by individual optimization of each objective.

In single-objective optimization, Tables 4 and 8 show that the regional planning is only slightly better (about $1 \%$ ) than the prefectural one with respect 
Table 8

The single-objective optimal solutions of the regional planning

\begin{tabular}{|c|c|c|c|c|c|}
\hline & GHE (min) & FIDI (min) & $\mathrm{ER}(\max )$ & MR $(\max )$ & $\mathrm{TC}(\min )$ \\
\hline $\begin{array}{l}\text { Objective } \\
\text { value }\end{array}$ & $11,982.8$ & 967.1 & 231,649 & 236,979 & $66,580.8$ \\
\hline $\begin{array}{l}\text { Transfer } \\
\quad \text { station }\end{array}$ & $\begin{array}{l}\text { Achinos, Achladochori, Alistrati, } \\
\text { Amfipolis, Ano Vrondou, Andigonides } \\
\text { (Kavasila), Arnea, Agios Athanasios } \\
\text { (Gefira), Edessa, Exaplatanos, Ierisos, } \\
\text { Anatolikos Olympos (Leptokaria), } \\
\text { Leianovergi, Livadia, Nea Michaniona, } \\
\text { Mouriai, Nea Kallikratia, Nea Moudania, } \\
\text { Neo Petritsi, Nikitas, Polikastro, Profitis, } \\
\text { Makedonida (Rizomata), SE GTA, } \\
\text { Toroni (Sikia), Sindos, Vrasna, West } \\
\text { GTA. }\end{array}$ & $\begin{array}{l}\text { (as in the solution of min. } \\
\text { GHE) }\end{array}$ & $\begin{array}{l}\text { (as in the solution of min. } \\
\text { GHE) }\end{array}$ & $\begin{array}{l}\text { (as in the solution of min. } \\
\text { GHE) }\end{array}$ & $\begin{array}{l}\text { (as in the solution of min. } \\
\text { GHE) }\end{array}$ \\
\hline$M R F$ & $\begin{array}{l}\text { Katerini }^{\mathrm{b}}, \text { Poligiros }^{\mathrm{b}}, \text { Serres }^{\mathrm{b}}, \text { Sindos } \mathrm{IA}^{\mathrm{b}} \text {, } \\
\text { Thermi IA }^{\mathrm{b}} \text {, Veroia } \\
{ }^{\mathrm{b}}, \text { Giannitsa }^{\mathrm{b}}\end{array}$ & 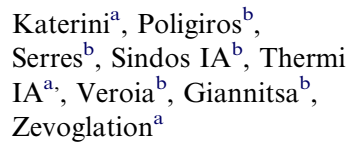 & $\begin{array}{l}\text { Kassandria }^{\mathrm{a}}, \text { Katerini }^{\mathrm{a}} \\
\text { Meliki }^{\mathrm{a}}, \text { Zevgolation }^{\mathrm{a}}\end{array}$ & $\begin{array}{l}\text { Kassandria }^{\mathrm{a}}, \text { Katerini }^{\mathrm{a}} \\
\text { Meliki }^{\mathrm{a}}, \text { Thermi IA }^{\mathrm{a}} \text {, } \\
\text { Giannitsa }^{\mathrm{b}}, \text { Zevgolation }^{\mathrm{a}}\end{array}$ & - \\
\hline ICRT & - & Sindos $\mathrm{IA}^{\mathrm{c}, \mathrm{d}}$ & Sindos $\mathrm{IA}^{\mathrm{c}}$ & - & - \\
\hline Landfill & $\begin{array}{l}\text { Axioupoli, Katerini, Kilkis, Kolindros, } \\
\text { Koufalia, Lachanas (Mavrorachi), } \\
\text { Makrochorion, Poligiros, Serres, } \\
\text { Giannitsa }\end{array}$ & $\begin{array}{l}\text { Axioupoli, Kilkis, } \\
\text { Kolindros, Koufalia, } \\
\text { Lachanas } \\
\text { (Mavrorachi), } \\
\text { Makrochorion, Poligiros, } \\
\text { Serres, Giannitsa }\end{array}$ & $\begin{array}{l}\text { Xirochori, Axioupoli, } \\
\text { Kilkis, Kolindros, Lachanas } \\
\text { (Mavrorachi), Litohoro, } \\
\text { Makrochorion, Meliki, } \\
\text { Pella, Poligiros, Giannitsa, } \\
\text { Zevgolation }\end{array}$ & $\begin{array}{l}\text { Axioupoli, Kilkis, } \\
\text { Kolindros, Langadas, } \\
\text { Makrochorion, Pella, } \\
\text { Poligiros, Zevgolation }\end{array}$ & $\begin{array}{l}\text { Vrasna, Axioupoli, } \\
\text { Kasandria, Katerini, } \\
\text { Kilkis, Kolindros, } \\
\text { Koufalia, Lachanas } \\
\text { (Mavrorachi), } \\
\text { Makrochorion, Meliki, } \\
\text { Poligiros, Serres, } \\
\text { Giannitsa, Zevgolation }\end{array}$ \\
\hline
\end{tabular}

\footnotetext{
** Production of RDF; ${ }^{+++}$Pyrolysis and Gasification.

a Anaerobic digestion.

b Composting.

${ }^{c}$ Mass burn.

${ }^{\mathrm{d}}$ Rotary kiln.
} 
to all objectives: energy recovery $(0.43 \%)$, material recovery $(0.76 \%)$, total cost $(1.08 \%)$, greenhouse emission $(0.02 \%)$, and final disposal $(0.02 \%)$. A low level of collaboration between the prefectures is the main reason for these insignificant differences. In a problem with higher collaboration between prefectures, the regional plan would be more clearly superior to the prefectural plan.

A fair solution is summarized in Table 9 for the region. Table 10 suggests that $66.86 \%$ of waste goes to the final disposal at the sanitary landfills while $41.8 \%$ of it goes directly from the waste producers. Moreover, building an incinerator (of any type) is not recommended. We also show the detailed solution for the Pella prefecture in Fig. 6. This figure shows the inter-prefectural collaboration between Pella and Imathia, where waste flows from Leianovergi (in Imathia) and Krya Vrisi (in Pella) to Giannitsa (in Pella) and Makrochorion (in Imathia).

Table 11 contrasts the fair solutions for prefectural and regional solid waste management planning. This table shows that regional plan does not dominate prefectural plan (in fact, the regional plan is better only in the total cost objective). The regional plan has $5.4 \%$ more disposal to sanitary landfills than the prefectural plan. Consequently the regional plan requires more sanitary landfills and produces $4.8 \%$ more greenhouse emissions. Less waste flow to MRF facilities also explains why the regional plan recovers less material and energy. Note that a composting MRF does not recover energy and the material recovery coefficient of an anaerobic digestion MRF is three times higher than its energy coefficient. Therefore, the prefectural plan recovers only slightly $(0.31 \%)$ more energy but recovers significantly $(5.7 \%)$ more materials than the regional plan. Nevertheless, the smaller number of MRFs results in the regional plan costing $7.1 \%$ less than the prefectural plan.

However, note that the analysis so far is based on the fairness concept. If we ignore the fairness issue, it is possible to generate a regional solution that costs more, but recovers more energy and/or material than the current one. For example, the solution that maximizes the material recovery in Table 8 reduces the greenhouse emission from 19,573.6 to $15,565.2$ (by $20.5 \%$ ), reduces disposal from $66.9 \%$ to $44.1 \%$, and increases material recovery from 123,992 to 236,976 (by $47.7 \%$ ), in comparison to the solution from Table 11. Yet these benefits come at a steep increase in cost from 172,726 to 280,377 (by $38.4 \%$ ) and decrease in energy recovery from 144,403 to 123,470 (by $14.5 \%$ ). To allow for a thor-

Table 9

Fair locations for MSW facilities in the region of Central Macedonia

\begin{tabular}{llllll}
\hline & GHE & FIDI & ER & MR & TC \\
\hline Objective value & $19,573.6$ & $1,491.04$ & 144,403 & 123,992 & 172,726
\end{tabular}

Location decisions $\quad$ TS: Achinos, Achladochori, Alistrati, Amfipolis, Ano Vrondou, Andigonides (Kavasila), Arnea, Agios Athanasios (Gefira), Edessa, Exaplatanos, Ierisos, Anatolikos Olympos (Leptokaria), Leianovergi, Livadia, Nea Michaniona, Mouriai, Nea Kallikratia, Nea Moudania, Neo Petritsi, Nikitas, Polikastro, Profitis, Makedonida (Rizomata), SE GTA, Toroni (Sikia), Sindos, Vrasna, West GTA.

MRF: Katerini ${ }^{\mathrm{a}}$, Thermi IA ${ }^{\mathrm{a}, \mathrm{b}}$

ICRT:

Sanitary landfill: Agios Antonios, Axioupoli, Kassandria, Kilkis, Kolindros, Koufalia, Langadas, Makrochorion, Meliki, Poligiros, Serres, Vrasna, Giannitsa, Zevgolation

\footnotetext{
${ }^{* *}$ Composting; ${ }^{+}$mass burn; ${ }^{++}$rotary kiln; ${ }^{+++}$pyrolysis and gasification.

${ }^{a}$ Anaerobic digestion.

b Production of RDF.
}

Table 10

Fair waste flow distribution among the MSW facilities in the region of Central Macedonia

\begin{tabular}{|c|c|c|c|c|c|c|c|c|}
\hline WP-TS & WP-MRF* & $\mathrm{WP}-\mathrm{MRF}^{* *}$ & $\mathrm{WP}-\mathrm{MRF}^{* * *}$ & WP-ICRT & WP-SL & TS-MRF ${ }^{*}$ & TS-MRF ${ }^{* *}$ & TS-MRF ${ }^{* * *}$ \\
\hline 374.881 & 702.019 & 0 & 530 & 0 & 623.35 & 0 & 0 & 0 \\
\hline TS-ICRT & & TS-SL & $\mathrm{MRF}^{*}-\mathrm{SL}$ & \multicolumn{2}{|c|}{$\mathrm{MRF}^{* *}-\mathrm{SL}$} & \multicolumn{2}{|c|}{$\mathrm{MRF}^{* * *}-\mathrm{SL}$} & ICRT-SL \\
\hline 0 & & 374.881 & 280.808 & \multicolumn{2}{|l|}{0} & \multicolumn{2}{|l|}{212} & 0 \\
\hline
\end{tabular}




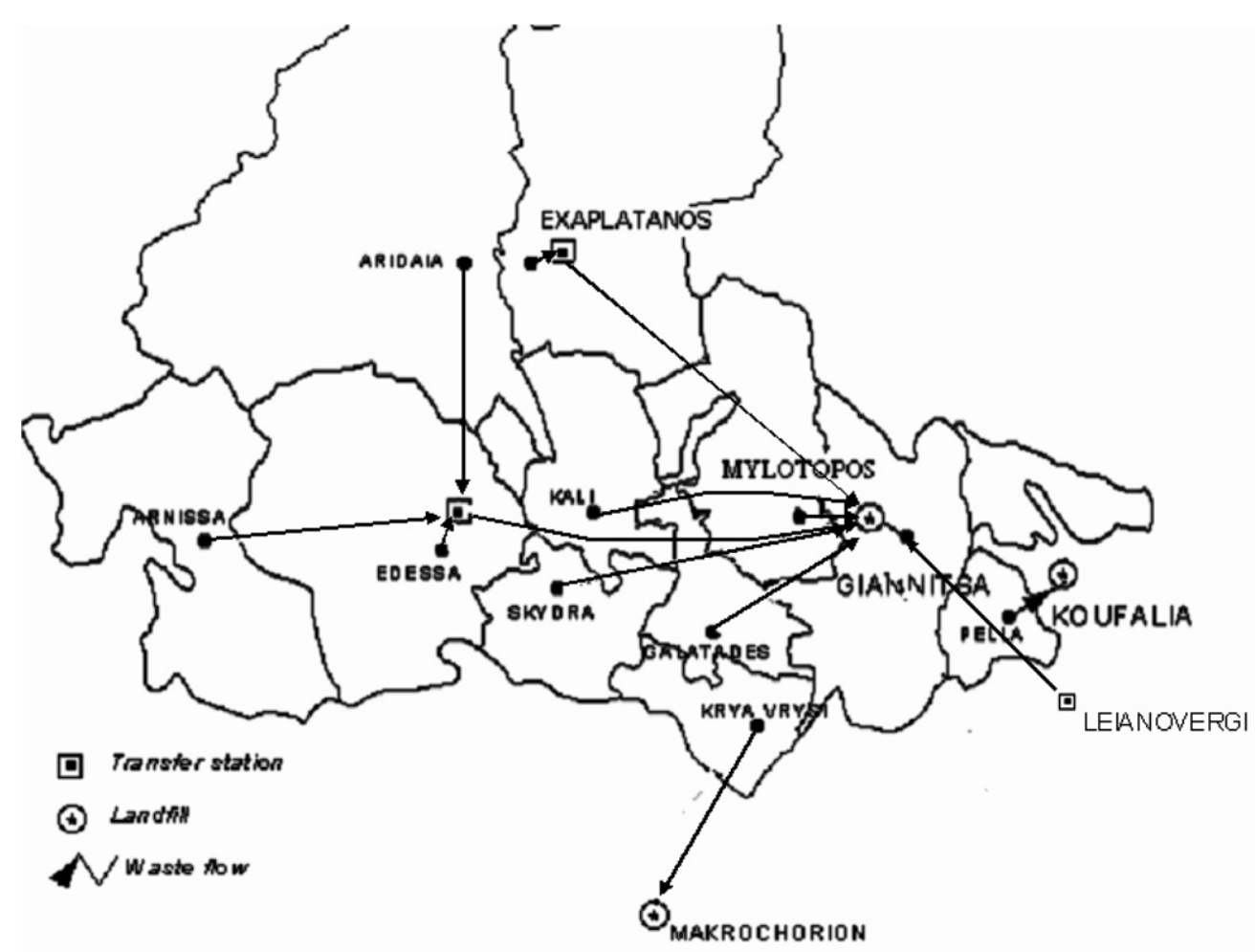

Fig. 6. MSW management of the prefecture of Pella in accordance with the best compromise solution for the region of Central Macedonia, where the inter-prefectural collaboration of the prefecture of Pella with the prefecture of Imathia (with waste flows from Platy to Leianovergie and from Krya Vrisi to Makrochorion) is also illustrated.

ough analysis of tradeoffs such as these, as well as deciding whether or not prefectural cooperation is worth the effort, participation by the DM is necessary.

Table 11

The fair solutions for Prefectural vs. Regional MSW planning

\begin{tabular}{lll}
\hline & Sum over all prefectures under prefectural planning & Region of Central Macedonia \\
\hline \# WP & 134 & 134 \\
\# TS & 28 & 28 \\
\# MRF & $5^{\mathrm{a}}+1^{\mathrm{b}}+1^{\mathrm{c}}$ & $2^{\mathrm{a}}+1^{\mathrm{c}}$ \\
\# ICRT & 0 & 0 \\
\# SL & 13 & 14 \\
Total waste flow to MRF* & 725.7964 & 702.019 \\
Total waste flow to MRF** & 80 & 0 \\
Total waste flow to MRF** & 559.739 & 530 \\
Total waste flow to ICRT & 0 & 0 \\
Total waste flow to Sanitary landfill & $1,410.93$ & 1491.04 \\
GHE & $\mathbf{1 8 , 6 3 2 . 6 0}$ & $19,573.6$ \\
FIDI & $\mathbf{1 , 4 1 0 . 9 3}$ & $1,491.04$ \\
ER & $\mathbf{1 4 4 , 8 5 6 . 5 4}$ & 144,403 \\
MR & $\mathbf{1 3 1 , 4 7 6 . 0 0}$ & 123,992 \\
TC & $185,993.72$ & $\mathbf{1 7 2 , 7 2 6}$
\end{tabular}

${ }^{+}$Mass burn; ${ }^{++}$rotary kiln; ${ }^{+++}$pyrolysis and gasification.

a Anaerobic digestion.

b Composting.

c Production of RDF 


\section{Concluding remarks}

We presented a new mixed-integer multipleobjective linear programming model, which helps to solve the location-allocation problem of municipal solid waste management facilities in the Central Macedonia region in North Greece. We considered five objectives: (1) minimize the greenhouse effect, (2) minimize the amount of final disposal, (3) maximize the amount of energy recovery, (4) maximize the amount of material recovery, and (5) minimize the total opening, transportation, and processing costs. The multiobjective problem is formulated as a lexicographic minimax problem in order to find a fair nondominated solution, a solution with all normalized objectives as equal as possible. We discussed how to replace the original lexicographic minimax problem with the lexicographic minimum problem.

The model is applied to compare and contrast the prefectural and regional planning for MSW management. Obviously, it is possible to get better results with the regional plan than the prefectural plan since the feasible region of the regional plan is a relaxation of that of the prefectural plan. However, our computational experiments with data from Central Macedonia show that the gains achieved by moving from prefectural to regional plan are minimal since the waste flow between prefectures is small. Of course, this depends on the data and there may be other instances where regional plans dominate prefectural plans by a wider margin. Assuming that all objective functions are equally important, the regional plan we generated is superior to our prefectural plan only on the total cost objective.

An immediate extension of this research would be to involve DMs in finding the best compromise solution. In this case, more attractive solutions than those presented in this paper may be achieved. As well, other interactive approaches to solving the MOMP problem can be applied and compared. Another possible extension is to apply the model to solve the problem of regional hazardous waste management, which might require only a mild modification on the set of constraints. However, in that case transportation and disposal risks as well as social opposition must be taken into account.

\section{Acknowledgements}

This research was supported by Natural Sciences and Engineering Research Council of Canada and the Greek Ministry of Development. The authors are also grateful to three anonymous referees and the guest editor for their comments which helped improve this manuscript.

\section{Appendix}

\section{Waste producer}

I set of locations of waste producers

$a_{i} \quad$ quantity of waste (in ton/day) produced by a waste producer $i \in I$

\section{Transfer station}

$\Pi \quad$ set of possible sites for the location of a transfer station

$M \quad$ set of possible typologies for a transfer station

$\varphi_{\pi}^{\mu} \quad$ binary variable for locating a transfer station at site $\pi \in \Pi$ with typology $\mu \in M$

$\alpha_{i \pi}^{\mu} \quad$ quantity of incompact waste (in ton/day) generated by a waste producer $i \in I$ and carried to a transfer station located at site $\pi \in \Pi$ with typology $\mu \in M$

$b_{\pi}^{\mu} \quad$ waste flow (in ton/day) variable from all waste producers to transfer station $\pi$ at site $\mu$, i.e., $b_{\pi}^{\mu}=\sum_{i \in I} \alpha_{i \pi}^{\mu}$

$\underline{k}_{\pi}^{\mu} \quad$ lower limit capacity (in ton/day) of local transfer station at site $\pi \in \Pi$ with typology $\mu \in M$

$\bar{k}_{\pi}^{\mu} \quad$ upper limit capacity (in ton/day) of local transfer station at site $\pi \in \Pi$ with typology $\mu \in M$

$p^{\varphi} \quad$ maximum number of opened transfer stations

\section{Material Recovery Facility (MRF)}

$P \quad$ set of possible sites for the location of a MRF

$V \quad$ Set of possible typologies for a MRF

$\chi_{\rho}^{v} \quad$ binary variable for locating a MRF at site $\rho \in P$ with typology $v \in V$

$\varepsilon_{i \rho}^{v} \quad$ quantity of waste (in ton/day) variable generated by a waste producer $i \in I$ and carried to a MRF located at site $\rho \in P$ with typology $v \in V$

$\varsigma_{\pi \rho}^{\mu \nu} \quad$ waste flow (in ton/day) variable from a transfer station located at site $\pi \in \Pi$ with typology $\mu \in M$ to a MRF at site $\rho \in P$ with typology $v \in V$

$c_{\rho}^{v} \quad$ waste flow (in ton/day) variable to a MRF at site $\rho \in P$ with typology $v \in V$, i.e., waste flow from all waste producers and transfer 
stations to a MRF at site $\rho \in P$ with typol$\operatorname{ogy} v \in V$, i.e. $c_{\rho}^{v}=\sum_{i \in I} \varepsilon_{i \rho}^{v}+\sum_{\mu \in M} \sum_{\pi \in \Pi} \varsigma_{\pi \rho}^{\mu \nu}$ $\underline{g}_{\rho}^{v} \quad$ lower limit capacity (in ton/day) of a MRF at site $\rho \in P$ with typology $v \in V$

$\bar{g}_{\rho}^{v} \quad$ upper limit capacity (in ton/day) of a MRF at site $\rho \in P$ with typology $v \in V$

$s_{\rho}^{v} \quad$ waste and residue (in ton/day) variable from a MRF at site $\rho \in P$ with typology $v \in V$, i.e.

$s_{\rho}^{v}=\sum_{o \in O} \sum_{\tau \in T} \kappa_{\rho \tau}^{v o}$

See the definition of $\kappa_{\rho \tau}^{v o}$ below

$A_{v}^{\mathrm{GHE}} \quad$ emission coefficients for greenhouse effects (in ton of $\mathrm{CO}_{2}$-equivalent of $\mathrm{CO}_{2}$ and $\mathrm{CH}_{4}$ day/ton of waste year) from an MRF with typology $v \in V$

$A_{v}^{\mathrm{E}} \quad$ energy recovery coefficient (in MW h day/ ton year) from an MRF with typology $v \in V$

$A_{v}^{\mathrm{M}} \quad$ coefficient for calculating the material recovery (ton.day/ton of waste year) from an MRF with typology $v \in V$

$f^{v} \quad$ efficiency degree of MRF. It is assumed that $f^{v}=0.4$

$p^{\chi} \quad$ maximum number of opened MRFs

Incinerator (waste to energy facility)

$D \quad$ set of possible sites for the location of an incinerator

$E \quad$ set of possible typologies for an incinerator

$\psi_{\sigma}^{\xi} \quad$ binary variable for locating an incinerator at site $\sigma \in D$ with typology $\xi \in E$

$\zeta_{i \sigma}^{\xi}$ quantity of waste (in ton/day) variable generated by a waste producer $i \in I$ and carried to an incinerator located at site $\sigma \in D$ with typology $\xi \in E$

$\theta_{\pi \sigma}^{\mu \xi} \quad$ waste flow (in ton/day) variable from a transfer station located at site $\pi \in \Pi$ with typology $\mu \in M$ to an incinerator at site $\sigma \in D$ with typology $\xi \in E$

$d_{\sigma}^{\xi} \quad$ waste flow (in ton/day) variable to an incinerator at site $\sigma \in D$ with typology $\xi \in E$, i.e., waste flow from all waste producers and transfer stations to an incinerator at site $\sigma \in D$ with typology $\xi \in E$, i.e. $d_{\sigma}^{\xi}=\sum_{i \in I} \zeta_{i \sigma}^{\xi}+\sum_{\mu \in M} \sum_{\pi \in \Pi} \theta_{\pi \sigma}^{\mu \xi}$

$\underline{h}_{\sigma}^{\xi} \quad$ lower limit capacity (in ton/day) of incinerator at site $\sigma \in D$ with typology $\xi \in E$

$\bar{h}_{\sigma}^{\xi} \quad$ upper limit capacity (in ton/day) of incinerator at site $\sigma \in D$ with typology $\xi \in E$

$q_{\sigma}^{\xi} \quad$ waste flow (in ton/day) from an incinerator at site $\sigma \in D$ with typology $\xi \in E$
$\Gamma_{\xi}^{\mathrm{GHE}}$ emission coefficients for greenhouse effects (in ton of $\mathrm{CO}_{2}$-equivalent of $\mathrm{CO}_{2}$ and $\mathrm{CH}_{4}$ day/ton of waste year) from facilities in an incinerator with typology $\xi \in E$

$\Gamma_{\xi}^{\mathrm{E}} \quad$ Energy recovery coefficients (in MW h day/ ton year) from an incinerator with typology $\xi \in E$

$\Gamma_{\xi}^{\mathrm{M}} \quad$ Material recovery coefficients (ton.day/ton of waste.year) from an incinerator with typology $\xi \in E$

$f^{\xi} \quad$ Efficiency degree of an incinerator. It is assumed that $f^{\xi}=0.4$

$p^{\psi} \quad$ Maximum number of opened incinerators

\section{Sanitary landfill}

$T \quad$ Set of possible sites for the location of a landfill

$O \quad$ Set of possible typologies for a landfill

$\omega_{\tau}^{o} \quad$ Binary variable for locating a landfill at site $\tau \in T$ with typology $o \in O$

$\eta_{i \tau}^{o} \quad$ Quantity of waste (in ton/day) variable generated by a waste producer $i \in I$ and carried to a landfill located at site $\tau \in T$ with typology $o \in O$

$\imath_{\pi \tau}^{\mu o} \quad$ Compacted waste flow (in ton/day) variable from a transfer station at site $\pi \in \Pi$ with typology $\mu \in M$ to a landfill at site $\tau \in T$ with typology $o \in O$

$\kappa_{\rho \tau}^{v o} \quad$ Waste residue flow (in ton/day) variable from a MRF at site $\rho \in P$ with typology $v \in V$ to a landfill at site $\tau \in T$ with typology $o \in O$

$\delta_{\sigma \tau}^{\xi o} \quad$ Waste residue flow (in ton/day) variable from an incinerator at site $\sigma \in D$ with typology $\xi \in E$ to a landfill at site $\tau \in T$ with typology $o \in O$

$e_{\tau}^{o} \quad$ Waste flow (in ton/day) variable to a landfill at site $\tau \in T$ with typology $o \in O$, i.e. waste flow from all waste producers, all transfer stations, all MRFs, and all incinerators to landfill at site $\tau \in T$ with typology $o \in O$, i.e., $e_{\tau}^{o}=\sum_{i \in I} \eta_{i \tau}^{o}+\sum_{\mu \in M} \sum_{\pi \in \Pi} l_{\pi \tau}^{\mu o}+$ $\sum_{v \in V} \sum_{\rho \in P} \kappa_{\rho \tau}^{v o}+\sum_{\xi \in E} \sum_{\sigma \in D} \delta_{\sigma \tau}^{\xi o}$

$\underline{u}_{\tau}^{o} \quad$ Lower limit capacity (in ton/day) of a landfill at site $\tau \in T$ with typology $o \in O$

$\bar{u}_{\tau}^{o} \quad$ Upper limit capacity (in ton/day) of a landfill at site $\tau \in T$ with typology $o \in O$

$E_{o}^{\mathrm{GHE}} \quad$ Emission coefficients for greenhouse effects (in ton of $\mathrm{CO}_{2}$-equivalent of $\mathrm{CO}_{2}$ and $\mathrm{CH}_{4}$. day/ton of waste.year) from facilities in a landfill with typology $o \in O$ 
$E_{o}^{\mathrm{E}} \quad$ Energy recovery coefficients (in MW h day/ ton year) from a landfill with typology $o \in O$

$p^{\omega} \quad$ Maximum number of opened sanitary landfills

$\mathrm{CFF}_{j k}^{i} \quad$ Installation cost (in Euro/ton) of facility $j$ at site $k$ with typology $i$ where $j \in\{\varphi, \chi$, $\psi, \omega\}, k \in\{\pi, \rho, \sigma, \tau\}$, and $i \in\{\mu, v, \xi, o\}$

CFVtp ${ }_{j j^{\prime} k k^{\prime}}^{i i^{\prime}}$ Transportation cost (in Euro/ton) from facility $j$ at site $k$ with typology $i$ to facility $j^{\prime}$ at site $k^{\prime}$ with typology $i^{\prime}$ where $j \neq$ $j^{\prime} \in\{\varphi, \chi, \psi, \omega\}, \quad k \neq k^{\prime} \in\{\pi, \rho, \sigma, \tau\}, \quad$ and $i \neq i^{\prime} \in\{\mu, v, \xi, o\}$. The transportation cost may not dependent on typology

$\mathrm{CFVtr}_{j k}^{i}$ Treatment cost (in Euro/ton) of the waste/residue of facility $j$ at site $k$ with typology $i$ where $j \in\{\varphi, \chi, \psi, \omega\}, k \in\{\pi, \rho$, $\sigma, \tau\}$, and $i \in\{\mu, v, \xi, o\}$

\section{References}

[1] L.E. Anderson, A.K. Nigam, A mathematical model for the optimization of a waste management system, ORC 67-25, Operations Research Center, University of California, Berkeley, 1967.

[2] A.P. Antunes, Location analysis helps manage solid waste in central Portugal, Interfaces 29 (4) (1999) 32-43.

[3] M. Barlaz, G.C. Cekander, N.C. Vasuki, Integrated solid waste management in the United States, Journal of Environmental Engineering 129 (2003) 583-584.

[4] C. Caruso, A. Colorni, M. Paruccini, The regional urban solid waste management system: A modeling approach, European Journal of Operational Research 70 (1) (1993) 1630.

[5] S. Chambal, M. Shoviak, A.E. Thal Jr., Decision analysis methodology to evaluate integrated solid waste management alternatives, Environmental Modeling \& Assessment 8 (2003) 25-34.

[6] Common Ministerial Decision, Measurements and terms for solid waste management, National planning for solid waste management (in Greek), Government Paper 1909, CMD 50910/2727, 2003.

[7] M. Ehrgott, Discrete decision problems, multiple criteria optimization classes and lexicographic max-ordering, in: T.J. Stewart, R.C. van den Honert (Eds.), Trends in Multicriteria Decision Making, Lecture Notes in Economics and Mathematical Systems, vol. 465, Springer, Berlin, 1998, pp. 31-44.

[8] M. Ehrgott, Multicriteria Optimization. Lecture Notes in Economics and Mathematical Systems, vol. 491, Springer Verlag, Berlin, 2000.

[9] M. Ehrgott, Lexicographic max-ordering - a solution concept for multicriteria combinatorial optimization, in: D. Schweigert (Eds.), Methods of Multicriteria Decision Theory, Proceedings of the 5th Workshop of the DGORWorking Group Multicriteria Optimization and Decision Theory, 1995, pp. 55-66.
[10] H.W. Gottinger, A computational model for solid waste management with application, European Journal of Operational Research 35 (3) (1988) 350-364.

[11] B.P. Helms, R.M. Clark, Locational models for solid waste management, Journal of Urban Planning and Development Division 97/SA2 (1971).

[12] J. Hokkanen, P. Salminen, Choosing a solid waste management system using multicriteria decision analysis, European Journal of Operational Research 98 (1) (1997) 19-36.

[13] A. Karagiannidis, N. Moussiopoulos, A model generating framework for regional waste management taking local peculiarities explicitly into account, Location Science 6 (1998) 281-305.

[14] A. Karagiannidis, P. Korakis, L. Katsameni, N. Moussiopoulos, Data bank and criteria for evaluating scenarios of regional solid waste management, in: Proceedings of the Fifth National Conference for Renewable Energy Sources, Athens, November, 1996, pp. 8-11.

[15] Ö. Kirca, N. Erkip, Selecting transfer station locations for large solid waste systems, European Journal of Operational Research 35 (3) (1988) 339-349.

[16] R.S. Klein, H. Luss, D.R. Smith, A lexicographic minimax algorithm for multiperiod resource allocation, Mathematical Programming 55 (1992) 213-234.

[17] H. Luss, On equitable resource allocation problems: A lexicographic minimax approach, Operations Research 47 (3) (1999) 361-378.

[18] E. Marchi, J.A. Oviedo, Lexicographic optimality in the multiple objective linear programming: The nucleolar solution, European Journal of Operational Research 57 (1992) 355-359.

[19] W. Ogryczak, On the lexicographic minimax approach to location problems, European Journal of Operational Research 100 (1997) 566-585.

[20] W. Ogryczak, Location problems from the multiple criteria perspective: Efficient solutions, Archives of Control Sciences 7 (XLIII) (1998) 161-180.

[21] W. Ogryczak, M. Pióro, A. Tomaszewski, Telecommunications network design and max-min optimization problem, Journal of Telecommunications and Information Technology 3 (2005) 43-56.

[22] W. Ogryczak, T. Śliwiński, On equitable approaches to resource allocation problems: The conditional minimax solution, Journal of Telecommunications and Information Technology 3 (2002) 40-48.

[23] M. Pióro, M. Dzida1, E. Kubilinskas, P. Nilsson, W. Ogryczak, A. Tomaszewskil, M. Zagożdżon, Applications of the max-min fairness principle in telecommunication network design, First Conference on Next Generation Internet Networks Traffic Engineering (NGI 2005), Rome, Italy, 18-20 April, 2005.

[24] J.A.M. Potters, S.H. Tijs, The nucleolus of a matrix game and other nucleoli, Mathematics of Operations Research 17 (1992) 164-174.

[25] Sanitation country profile, Greece. (Downloaded from website http://www.un.org/esa/agenda21/natlinfo/countr/ greece/greecesanitation04f.pdf).

[26] R.R. Yager, On ordered weighted averaging aggregation operators in multicriteria decision making, IEEE Transactions on Systems Man and Cybernetics 18 (1988) 183190. 